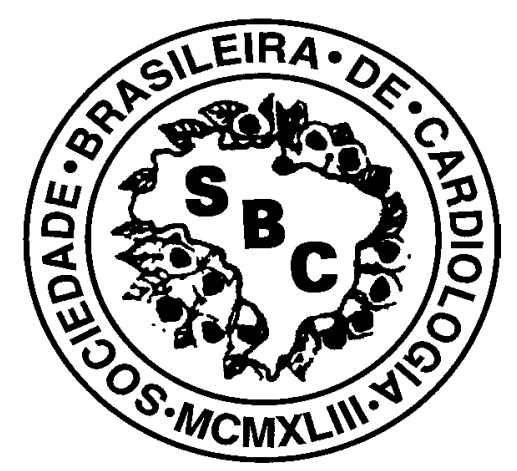

Diretriz para Indicações e Utilização da Ecocardiografia na Prática Clínica 


\title{
Diretriz para Indicações e Utilização da Ecocardiografia na Prática Clínica
}

\author{
Editor \\ Orlando Campos Filho
}

\section{Co-editores}

Paulo Zielinsky, Juarez Ortiz

\author{
Membros \\ Benedito Carlos Maciel \\ José Lazaro Andrade \\ Wilson Mathias Jr. \\ Djair Falcão Brindeiro Filho \\ Jorge Eduardo Assef \\ Carlos T. Oliveira Lima \\ Márcia de Melo Barbosa \\ Valdir Ambrósio Moisés \\ Samira Mohry Borges \\ Sérgio Cunha Pontes \\ Rogério Tasca \\ Vera Márcia Gimenez \\ Iran Castro \\ Manuel Adan Gil \\ Adelaide Arruda-Olson \\ Jeane Mike Tsu-Tsui
}

\section{Coordenador}

Jorge Ilha Guimarães 


\section{Introdução}

As recomendações atuais para o uso prático da ecocardiografia nasceram de um consenso, originalmente editado pela Sociedade Brasileira de Cardiologia, em $1995^{1}$, posteriormente sistematizado, em 1997, em outro documento ${ }^{2}$, propondo critérios para solicitação de exames complementares, não como normas rígidas, mas sim como orientação para o cardiologista proceder a uma investigação diagnóstica racional e objetiva, baseada em parâmetros técnicos e éticos, com o mesmo propósito, coube à atual comissão representativa do Departamento de Ecocardiografia da SBC atualizar o texto, incorporando as inovações tecnológicas que têm se agregadoà rotina do exame ecocardiográfico e acrescentando a experiência sedimentada de novas evidências em medicina. Portanto, longe de ser definitivo, assim como os estudos anteriores ${ }^{1,2}$, este consenso é dinâmico e deverá ser constantemente aperfeiçoado, assimilando as permanentes transformações decorrentes do contínuo processo de evolução científica. Um extenso estudo semelhante, elaborado pelas Sociedades Americanas de Cardiologia, recentemente revisado ${ }^{3}$, também serviu de base para este consenso.

No desenvolvimento deste texto, o exame ecocardiográfico se refere à integração de todos seus elementos atuais (ecocardiograma uni e bidimensional, estudo do fluxo com Doppler espectral pulsátil e contínuo, e mapeamento do fluxo em cores), que constituem modalidades complementares e indissociáveis para um diagnóstico não invasivo completo e abrangente dos aspectos estruturais e funcionais do coração e grandes vasos. Tais modalidades estão presentes nos diversos procedimentos diagnósticos disponíveis: ecodopplercardiografia convencional transtorácica, ecocardiografia transesofágica, ecocardiografia sob estresse, ecocardiografia com contraste, ecocardiografia fetal, ecocardiografia intra-operatória e ecocardiografia intra-cardíaca. Para simplificação, o termo “ecocardiografia” abrangerá os títulos "Doppler-ecocardiografia" ou "ecodopplerecocardiografia", referidos de forma abreviada no texto como ECOouECO-D.

O valor do método foi analisado para cada doença, síndrome ou condição clínica, considerando-se os seguintes aspectos: impacto diagnóstico, contribuição no planejamento terapêutico e monitorização dos resultados, avaliação prognóstica e estratificação de risco, acompanhamento longitudinal de pacientes e, por fim, triagem de familiares, quando pertinente.

Sempre que possível, as recomendações foram pautadas nas evidências clínicas disponíveis. As indicações do exame obedeceram a critérios consagrados de classificação de evidências: Classe I: consenso unânime sobre indicação do exame, com valor diagnóstico comprovado; Classe IIa: aprovação da maioria, porém com algumas discordâncias na indicação; Classe IIb: divergências , com divisão de opiniões; Classe III: consenso de que o exame é desnecessário, ou quando não for aplicável.

Uma divisão dos temas foi feita para facilitar a consulta na prática diária, cujo conteúdo não pretendeu esgotar o assunto, apenas procurou organizar o uso dessa ferramenta diagnóstica versátil e indispensável na avaliação cardiológica não invasiva.

\section{Avaliação da Função Ventricular Esquerda e das Cardiomiopatias}

\subsection{Avaliação global da função ventricular esquerda}

1.1.1 Função sistólica - A indicação do estudo ecocardiográfico com o objetivo de avaliar a função sistólica ventricular esquerda corresponde a uma das principais aplicações clínicas deste método diagnóstico. A contratilidade ventricular representa o resultado de uma complexa interação entre o estado contrátil do músculo cardíaco e os níveis de pré e pós-carga. Tradicionalmente, avalia-se a função sistólica ventricular mediante análise da mobilidade segmentar da parede ventricular ou utilizando índices de desempenho da fase de ejeção, obtidos de forma simples e não invasiva, por meio do ecodopplercardiograma (ECO-D) como a fração de encurtamento sistólico ventricular (delta $\mathrm{D} \%$ ), a velocidade média de encurtamento circunferencial (Vcf), o volume ejetado por sístole (VS), o débito cardíaco (DC) e a fração de ejeção(FE), além dos índices de desempenho da fase isovolumétrica, como a velocidade máxima de elevação da pressão ventricular (dp/dt max) em presença de refluxo mitral ou tricúspide. A tensão parietal sistólica também pode ser estudada. Índices mais sofisticados, como a relação pressão-dimensão (ou pressão-volume) ventricular esquerdo ao final da sístole, podem ser obtidos de modo não invasivo, mediante a administração de drogas vasoativas e o uso da ecocardiografia modo-M.

A técnica bidimensional, que apresenta maior resolução espacial, possibilita caracterizar mais precisamente a fração de ejeção de um ventrículo esquerdo com geometria anormal. Embora, na prática clínica, a estimativa visual da fração de ejeção do VE seja freqüentemente utilizada, de modo semi-quantitativo, deve-se registrar que esta técnica depende fundamentalmente da experiência do examinador, estando mais sujeita a erros. A análise da mobilidade segmentar do ventrículo esquerdo pela ecocardiografia bidimensional representa uma técnica semi-quantitativa de avaliação da função sistólica regional, que se tem mostrado de grande valor na prática clínica, especialmente, na ecocardiografia sob estresse. Esta técnica depende da análise de espessamento da parede ventricular e da mobilidade endocárdica, apresentando, deste modo, a mesma dependência das cargas impostas ao coração observada para os demais índices da fase de ejeção.

Outras técnicas disponíveis para análise da função sistólica envolvem o cálculo do débito cardíaco pelo Eco-D e a estimativa do dp/dt em vigência de insuficiência mitral. Recentemente, foi desenvolvido um índice de desempenho miocárdico, que integra elementos de função sistólica e diastólica, cuja utilidade encontra-se em estudos.

Métodos mais elaborados de análise global ou regional das funções sistólica e diastólica de ambos os ventrícu- 
los, envolvendo sofisticados processos de computação (strain, strain rate, tissue tracking), são muito promissores e ainda encontram-se na fase de pesquisa.

1.1.2 Função diastólica - Ultimamente tem sido valorizada a participação da disfunção diastólica na gênese das manifestações congestivas da insuficiência cardíaca, mesmo em pacientes com uma função sistólica preservada ${ }^{4-7}$. Admite-se, inclusive, que entre 30 e $40 \%$ dos pacientes com insuficiência cardíaca apresentem sinais de congestão pulmonar dependentes, fundamentalmente, de uma função diastólica anormal ${ }^{8-11}$. Além disso, tem sido demonstrado, em um número apreciável de condições clínicas, que a disfunção diastólica precede a disfunção sistólica ${ }^{12-15}$. Apesar do interesse e do volume de informações, a função diastólica ainda não é compreendida por completo. A diástole compreende um número amplo de elementos, que interagem de modo complexo, para resultar no enchimento ventricular: 0 relaxamento miocárdico ativo, a complacência ventricular, $o$ sincronismo regional ventricular, a sucção diastólica ventricular, as propriedades viscoelásticas do miocárdio, a contração atrial, a restrição pericárdica, a interação ventriculare o efeito erétil das coronárias ${ }^{16-19}$. Adicionalmente, os fatores que interferem na diástole são sensíveis às sobrecargas impostas ao coração durante o ciclo cardíaco e à contratilidade ventricular. A limitação dos métodos invasivos de avaliação do desempenho diastólico estimulou a busca por métodos não invasivos para esse fim. Na ecocardiografia, iniciou-se com o modo-M digitizado, depois passou-se às diversas técnicas com Doppler atualmente disponíveis, que envolvem a análise do padrão de fluxo diastólico mitral, o estudo do fluxo das veias pulmonares e, mais recentemente, a propagação do fluxo mitral e as velocidades do tecido miocárdico ventricular. Todas estas técnicas têm em comum a limitação de considerar apenas a variação de velocidade de fluxo ou de estruturas em função do tempo, sem levar em conta modificações da pressão intraventricular. O estudo das velocidades diastólicas do fluxo mitral são realizadas habitualmente pelo Doppler pulsátil, determinando as ondas $\mathrm{E}$ e $\mathrm{A}$, que caracterizam respectivamente as fases de enchimento rápido e contração atrial, e a relação entre ambas $(\mathrm{E} / \mathrm{A})^{20}$. Também são determinados os tempos de desaceleração do fluxo mitral e o tempo de contração isovolumétrica do ventrículo esquerdo. Assim, foi possível reconhecer quatro diferentes padrões de disfunção diastólica, com gravidade crescente: relaxamento ventricular diastólico alterado, padrão pseudo-normal e padrão restritivo de enchimento ventricular reversível e irreversível. O advento recente do Doppler tecidual pulsátil, avaliando as velocidades de movimentação do miocárdio ventricular, permitiu acrescentar novos índices de função diastólica, menos sensíveis a variações de carga. O fluxo de veias pulmonares e a velocidade de propagação do "Color M-mode" são técnicas também úteis na avaliação da função diastólica.

\subsection{Estimativa das pressões de enchimento ventricular}

Diferentes técnicas Doppler-ecocardiográficas têm sido empregadas com o objetivo de determinar a pressão de enchi- mento, incluindo a velocidade de fluxo transvalvar mitral, as curvas de velocidade de fluxo em veia pulmonar, o Modo M colorido, o Doppler tecidual e a resposta de velocidade de fluxo através da valva mitral em condições de sobrecarga ${ }^{21}$. Em pacientes com disfunção ventricular, documenta-se um encurtamento progressivo do tempo de desaceleração mitral e um aumento da relação E/A enquanto a complacência ventricular se reduze a pressão atrial esquerda aumenta. Correlação satisfatória também tem sido descrita para a velocidade $(\mathrm{A}>30 \mathrm{~cm} / \mathrm{s})$ ou duração (> 30 ms quando comparada com a onda $A$ do fluxo transvalvar) de fluxo retrógrado em veia pulmonar, bem como para a redução $(>0.5)$ da razão E/A mitral durante a manobra de Valsalva, o que não ocorre quando a função sistólica ventricular está preservada. Considerando que as velocidades tanto de fluxo de enchimento ventricular esquerdo quanto de veias pulmonares são influenciadas por múltiplos fatores, incluindo a pressão atrial esquerda, o relaxamento ventricular, as sobrecargas impostas ao coração, a interação ventricular, a freqüência cardíaca e a idade, outras variáveis têm sido testadas com o objetivo de estimar as pressões de enchimento ventricular. Entre estas, destaca-se a relação E/E', obtida entre as velocidades de fluxo inicial transvalvar mitral e do Doppler tecidual registrado no anel valvar mitral, que mostra uma boa correlação com os valores de pressão de enchimento ventricular, tanto em pressões elevadas $\left(\mathrm{E}^{-} \mathrm{E}^{\prime}>15\right)$ comonormais $\left(\mathrm{E}^{\prime} / \mathrm{E}^{\prime}<8\right)^{22}$. Domesmomodo, verifica-se uma excelente correlação entre a pressão atrial esquerda e o tempo de desaceleração da onda diastólica da veia pulmonar ${ }^{20}$.

\subsection{Esclarecimento de dispnéia ou edema de origem indeterminada}

A Doppler-ecocardiografia proporciona um conjunto de informações morfológicas e funcionais que são essenciais para, em consonância com os elementos de ordem clínica, estabelecer o diagnóstico diferencial da etiologia da insuficiência cardíaca, da disfunção ventricular ou de dispnéia e edema de natureza indeterminada. Com base na caracterização do envolvimento miocárdico, valvar ou pericárdico, bem como da análise das funções sistólica e diastólica ventricular ou, ainda, das modificações da geometria ventricular, é possível definir o diagnóstico etiológico na maior parte das situações clínicas. Em algumas condições, como ocorre na diferenciação entre pericardite constrictiva e cardiomiopatia restritiva, pode haver superposição de algumas características morfológicas e funcionais que tornam essa distinção mais difícil.

\subsection{Cardiomiopatia dilatada}

Os elementos estruturais e funcionais fundamentais para o estabelecimento do diagnóstico de cardiomiopatia dilatada são fornecidos pelo ecocardiograma: dilatação das cavidades sem aumento da espessura miocárdica, depressão global da função sistólica, graus variáveis de disfunção diastólica, regurgitações valvares por dilatação ostial, presença de trombos intracavitários, estimativas indiretas das pressões de enchimento ventricular e da pressão arterial sistólica pulmonar. Eventualmente, pacientes com cardiomiopatia isquêmica resultante de infartos múltiplos ou miocárdio cronicamente hibernante podem exibir aspectos ecocardiográficos semelhantes. O estudo pelo Doppler do pa- 
drão de enchimento ventricular na cardiomiopatia dilatada tem valor prognóstico: para uma mesma fração de ejeção, um tempo de desaceleração do fluxo mitral $<115 \mathrm{~ms}$ (padrão "restritivo") indica pior evolução e necessidade de transplante ${ }^{23}$. Exames periódicos podem revelar mudanças evolutivas e avaliar a resposta a intervenções farmacológicas. Nas formas hereditárias da doença, o exame pode auxiliar no rastreamento de casos frustros em familiares.

\subsection{Cardiopatia chagásica crônica}

A evolução da cardiopatia chagásica é heterogênea e lenta: aproximadamente $70 \%$ dos cardiopatas com envolvimento cardíaco leve, sem insuficiência cardíaca, permanecem clinicamente estáveis por períodos que variam entre 12 e 27 anos. Na forma cardíaca crônica, há um quadro funcional comparável ao observado nas miocardiopatias dilatadas idiopáticas: aumento das pressões de enchimento ventriculares, da artéria pulmonar e de capilares pulmonares; aumento dos volumes ventriculares e redução da fração de ejeção. A análise da mobilidade segmentar das paredes do ventrículo esquerdo evidencia um conjunto de alterações bastante varíavel em cardiopatas chagásicos crônicos. A discinesia apical pode ocorrer em 50 a $65 \%$ dos cardiopatas sintomáticos, hipocinesia ou acinesia apical em até $20 \%$ dos casos, hipo ou acinesia da parede póstero-inferior em $15 \mathrm{a} 20 \%$ dos pacientes e menos frequentemente da parede lateral ${ }^{24-26}$. Um padrão de hipocinesia difusa do ventrículo esquerdo pode ser documentado em 15 a $40 \%$ desses pacientes. Deve-se registrar em significativa parcela (31\%) dos cardiopatas chagásicos crônicos a ocorrência de anormalidades múltiplas da mobilidade segmentar ${ }^{24-27}$. Foi demonstrado ${ }^{28}$ um acentuado comprometimento da função sistólica do ventrículo direito nesses pacientes, que estava presente até mesmo em indivíduos em que a função sistólica ventricular esquerda estava preservada e nenhuma outra evidência de cardiopatia era manifesta. A ocorrência de aneurisma ventricular direito tem sido descrita em 10\% dos cardiopatas chagásicos estudados pela ecocardiografia.

A forma indeterminada da doença de Chagas vem sendo objeto de intensas investigações direcionadas no sentido de identificar, nesses pacientes, evidências de algum grau de envolvimento miocárdico ou digestivo. Entretanto, seus resultados acabaram por gerar inúmeras dúvidas quanto ao real significado dessas alterações, em função de diversos fatores: os critérios para inclusão dos pacientes na forma indeterminada não foram homogêneos; os eletrocardiogramas foram interpretados, não raramente, com muita liberalidade; havendo até, em alguns estudos, ausência de grupo controle. Nesses pacientes, em geral, os índices de desempenho sistólico global do ventrículo esquerdo estão dentro dos limites da normalidade, em condições basais. Discinesia ou hipocinesia apical tem sido relatada até 10 a $40 \%$ dos chagásicos indeter$\operatorname{minados}^{26,29}$. Hipocinesia da região póstero-apical do ventrículo esquerdo foi descrita como a alteração predominante em $22 \%$ dos casos, com hipocinesia difusa em 4\% ${ }^{27}$. Alguns relatam discreto aumento das dimensões e/ou menor desempenho sistólico do ventrículo esquerdo ${ }^{29,30}$, enquanto outros não mostram qualquer diferenciação entre normais e chagásicos indeterminados ${ }^{24,25}$.

A possibilidade de que portadores da forma indeter- minada da moléstia de Chagas revelassem disfunção sistólica ventricular esquerda, ao estudo ecocardiográfico, apenas quando submetidos a situações de estresse cardiovascular também foi explorada, como exercício isométrico ${ }^{24}$ ou estímulo vasopressor ${ }^{31}$. Parece que uma parcela substancial desses pacientes pode apresentar disfunção sistólica ventricular esquerda de magnitude discreta. É importante a observação de que os pacientes com anormalidades segmentares da mobilidade de parede ventricular tendem a apresentar índices de contratilidade persistentemente mais deprimidos que a média observada em chagásicos que não demonstram estas anormalidades. Os dados indicam que a presença de anormalidades segmentares ao ecocardiograma se constitua em um determinante fundamental de depressão contrátil do ventrículo esquerdo. O significado funcional e prognóstico dessas observações foi identificado em estudo que evidenciou progressão mais rápida da disfunção ventricular nesses pacientes ${ }^{31}$, sugerindo que a identificação de anormalidades segmentares de mobilidade de paredes ventriculares no ecocardiograma representa um marcador de pior prognóstico, fazendo com que o conceito de forma indeterminada da moléstia de Chagas, obrigatoriamente, deva considerar esse fato.

\subsection{Acompanhamento pós-transplante cardíaco}

O transplante cardíaco é, atualmente, o único tratamento consolidado para a insuficiência cardíaca refratária, ainda que esteja disponível apenas para uma pequena proporção dos pacientes acometidos por esta grave condição clínica. A Doppler-ecocardiografia tem sido utilizada no acompanhamento pós-cirúrgico de pacientes submetidos a transplante cardíaco em diferentes contextos. Não obstante algumas variáveis Doppler-ecocardiográficas convencionais (massa ventricular esquerda, tempo de relaxamento isovolumétrico, fração de encurtamento do VE, velocidade de encurtamento circunferencial, fração de ejeção, tempos de intervalos sistólicos) apresentarem um valor limitado ${ }^{32}$ para predição da ocorrência de rejeição em pacientes transplantados, a detecção precoce de disfunção diastólica pode ter um papel prognóstico nesses pacientes ${ }^{33}$. Por outro lado, esta técnica é útil na detecção de regurgitação tricúspide, que pode ocorrer na evolução do transplante cardíaco, na dependência da técnica cirúrgica empregada ${ }^{34}$. Após transplante cardíaco, a doença coronariana é a causa mais comum de complicação tardia, que pode determinar a morte ou um novo transplante. A ecocardiografia sob estresse tem se mostrado um método seguro e acurado para identificar os pacientes de alto risco para eventos cardíacos, mesmo em crianças ${ }^{35}$.

\subsection{Monitorização da função miocárdica durante quimiote- rapia com drogas cardiotóxicas}

Um grupo de agentes quimioterapêuticos efetivos, que incluem a doxorubicina, apresentam efeito cardiotóxico e podem desencadear uma cardiomiopatia dose-dependendente. Em face de seu caráter irreversível e cumulativo, a prevenção torna-se uma estratégia fundamental. A Doppler-ecocardiografia tem-se configurado como método não invasivo útil na avaliação de pacientes tratados com esses 


\begin{tabular}{|lc|}
\hline \multicolumn{1}{|c|}{$\begin{array}{c}\text { Tabela I - Indicações da ecocardiografia para avaliação da função } \\
\text { ventricular esquerda, de dispnéia e edema, e de cardiomiopatias }\end{array}$} \\
\hline Indicação & Classe \\
\hline $\begin{array}{l}\text { Avaliação das dimensões, espessura miocárdica e } \\
\text { função ventricular esquerda (sistólica e diastólica) } \\
\text { em pacientes com suspeita de cardiomiopatia ou } \\
\text { insuficiência cardíaca }\end{array}$ & I \\
$\begin{array}{l}\text { Avaliação de dispnéia ou edema com suspeita clínica } \\
\text { de envolvimento cardíaco }\end{array}$ & \\
$\begin{array}{l}\text { Pacientes expostos a substâncias cardiotóxicas, para } \\
\text { avaliação de comprometimento miocárdico ou para } \\
\text { orientação terapêutica }\end{array}$ & I \\
$\begin{array}{l}\text { Reavaliação da função ventricular em pacientes com } \\
\text { cardiomiopatia conhecida, quando há mudança na } \\
\text { condição clínica ou para orientação terapêutica } \\
\text { Reavaliação de pacientes com cardiomiopatia estabelecida } \\
\text { sem mudanças no estado Clínico }\end{array}$ & I \\
$\begin{array}{l}\text { Reavaliação de rotina em pacientes com cardiomiopatia } \\
\text { estável, sem perspectiva de mudança na orientação terapêutica }\end{array}$ & IIb \\
\hline
\end{tabular}

medicamentos. A monitorização da função ventricular esquerda antes e durante o período de tratamento tem sido empregada, embora os índices de função sistólica da fase de ejeção, quando analisados em condições basais, mostrem algumas limitações para a identificação precoce de toxicida$\mathrm{de}^{36}$. Alguns resultados promissores têm sido relatados quando se analisa a presença de disfunção diastólica ventricular, que parece preceder a redução da fração de ejeção ${ }^{37}$, bem como quando se investiga a função sistólica ventricular durante estudo ecocardiográfico sob estresse ${ }^{38}$.

\subsection{Cardiomiopatia hipertrófica}

A eco-D estabelece o diagnóstico da cardiomiopatia hipertrófica $(\mathrm{CMH})$ através da caracterização da hipertrofia ventricular, identificando seu grau e distribuição, e classificando os diversos tipos: septal assimétrica, apical, concêntrica ou mesoventricular. ODoppler é utilizado para localizar

\begin{tabular}{|c|c|}
\hline $\begin{array}{l}\text { Tabela II - Indicações da ecocardiografia na } \\
\text { cardiomiopatia hipertrófica }\end{array}$ & \\
\hline Indicação & Classe \\
\hline $\begin{array}{l}\text { Diagnóstico e classificação da CMH, avaliação da } \\
\text { repercussão hemodinâmica (obstrução sub-aórtica, } \\
\text { função diastólica, regurgitação mitral) }\end{array}$ & I \\
\hline $\begin{array}{l}\text { Reavaliação de pacientes com diagnóstico de } \mathrm{CMH} \\
\text { quando ocorre mudança documentada da sintomatologia }\end{array}$ & I \\
\hline $\begin{array}{l}\text { Avaliação de resultados terapêuticos de tratamento } \\
\text { farmacológico, cirúrgico (miectomia), procedimentos } \\
\text { intervencionistas (oclusão alcoólica da } 1^{\mathrm{a}} \text { septal) ou marcapasso }\end{array}$ & I \\
\hline $\begin{array}{l}\text { Reavaliação em pacientes com diagnóstico estabelecido } \\
\text { de MH e que estejam clinicamente estáveis }\end{array}$ & $\mathrm{IIb}$ \\
\hline $\begin{array}{l}\text { Reavaliação rotineira em paciente clinicamente estável em } \\
\text { quem não se contempla um mudança do manuseio }\end{array}$ & III \\
\hline Estudo de familiares do $1^{\circ}$ grau & I \\
\hline $\begin{array}{l}\text { Avaliação periódica de familiares durante a infância } \\
\text { e adolescência }\end{array}$ & IIa \\
\hline Avaliação periódica de familiares adultos & $\mathrm{IIb}$ \\
\hline
\end{tabular}

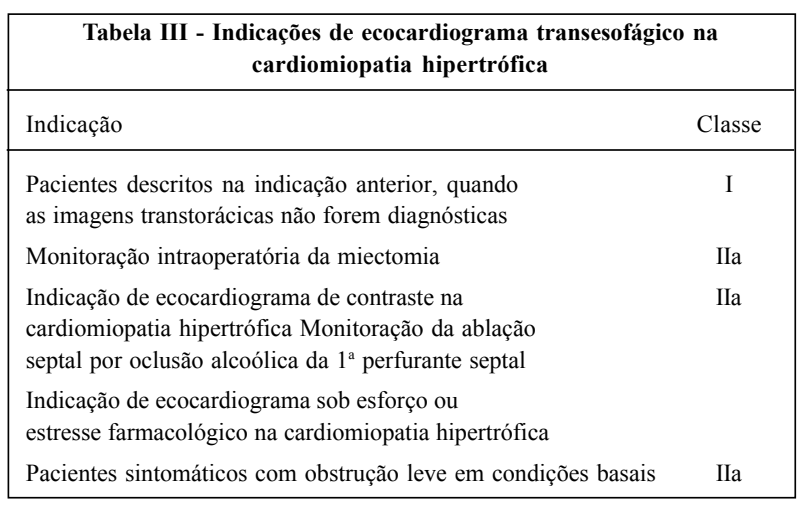

e quantificar a obstrução intraventricular quando presente (em repouso ou latente, induzida por manobras provocativas/medicamentos), detectar e quantificar a regurgitação mitral e avaliar a função diastólica pelo padrão de enchimento do ventrículo esquerdo pelo fluxo mitral ${ }^{39}$. A maioria dos pacientes apresenta padrão de relaxamento anormal; pacientes mais sintomáticos apresentam padrão "pseudonormal" e, excepcionalmente, alguns apresentam padrão restritivo (muito sintomáticos ou após a instalação de insuficiência cardíaca pós infarto). Outras técnicas mais específicas, como Doppler tecidual e velocidade de propagação do fluxo mitral pelo modo $\mathrm{Mem}$ cores podem ser usados para tal fim $^{40}$. Dado o caráter hereditário da CMH, justificam-se estudos de screening, que demostram prevalência da doença em $22 \%$ dos parentes de $1^{\circ}$. grau de portadores da CMH. As tabelas abaixo resumem as diversas indicações da ECO-D naCMH.

\subsection{Cardiomiopatia restritiva}

As cardiomiopatias restritivas (CMR) constituem um grupo de entidades, que incluem a CMR idiopática, a endomiocardiofibrose (EMF) a fibroelastose endomiocárdica e a endocardite parietal de Löefler, além das formas infiltrativas (amiloidose, sarcoidose, etc), as de armazenamento (hemocromatose, doença de Fabry, etc) e outras formas secundárias a diferentes processos patológicos ou terapêuticos (esclerodermia, síndrome carcinóide, metástases de neoplasias sistêmicas, toxicidade pela antraciclina, e cardiopatia por irradiação ${ }^{41}$. O diagnóstico pela ECO-D baseia-se nas alterações anatômicas e funcionais comuns: cavidades ventriculares de dimensão normal ou reduzida com disfunção

\begin{tabular}{|c|c|c|c|}
\hline \multicolumn{4}{|c|}{ Quadro I - Diagnóstico diferencial da EMF direita } \\
\hline Parâmetros & $\begin{array}{c}\text { EMF } \\
\text { direita }\end{array}$ & $\begin{array}{l}\text { Pericardite } \\
\text { constrictiva }\end{array}$ & $\begin{array}{l}\text { Doença de } \\
\text { Ebstein }\end{array}$ \\
\hline Fibrose & Presente & Ausente & Ausente \\
\hline Restrição diastólica & Presente & Presente & Ausente \\
\hline Valva tricúspide & Aderida & Normal & redundante \\
\hline Via de saída do VD & Dilatada & Normal & Dilatada \\
\hline Fluxo venoso sistêmico & Monofásico & Bifásico & não restritivo \\
\hline
\end{tabular}




\begin{tabular}{|lc|}
\hline \multicolumn{1}{|c|}{\begin{tabular}{c}
\multicolumn{1}{|c|}{ Tabela IV - Indicações da ecocardiografia na } \\
cardiomiopatia restritiva
\end{tabular}} & Classe \\
\hline Indicações & I \\
\hline $\begin{array}{l}\text { Investigação diagnóstica de pacientes com quadro } \\
\text { de ICC sem etiologia esclarecida }\end{array}$ & I \\
$\begin{array}{l}\text { Diagnóstico diferencial de pacientes com síndrome restritiva } \\
\text { Portadores de doenças sistêmicas potencialmente causadoras }\end{array}$ & I \\
de MR (forma associada) com clínica de ICC & I \\
$\begin{array}{l}\text { Pacientes com síndrome hipereosinofilica, ascite e turgência } \\
\text { das veias jugulares }\end{array}$ & I \\
$\begin{array}{l}\text { Pacientes submetidos à radioterapia com sinais de } \\
\text { hipertensão venosa sistêmica }\end{array}$ & I \\
$\begin{array}{l}\text { Reavaliação de pacientes com diagnóstico prévio de MR } \\
\text { quando há mudança do curso clínico da doença } \\
\text { Portadores de EMF para planejamento terapêutico e } \\
\text { avaliação prognóstica } \\
\text { Pacientes com edema e ascite, com pressão venosa sistêmica } \\
\text { normal e sem evidência de cardiopatia }\end{array}$ & Iia \\
\hline
\end{tabular}

diastólica do tipo restritivo ao Doppler, função sistólica global em geral preservada, e átrios dilatados. Observando-se aspectos estruturais peculiares de algumas doenças, é possível identificar a doença de base responsável pelo quadro restritivo, em conjunção com os dados epidemiológicos, clínicos e laboratoriais, e não raramente, com a anatomia patológica. Na CMR idiopática, o diagnóstico é feito por exclusão, e o diagnóstico diferencial principal é a pericardite constritiva. O Doppler tissular pode ser útil nessa situação ${ }^{42}$. $\mathrm{Na}$ amiloidose, há espessamento das valvas AV, paredes miocárdicas e eventualmente septo atrial, com reflexão mais intensa e aspecto granuloso do miocárdio. Na EMF, observam-se obliteração do ápice pela fibrose, sinais de restrição ventricular, envolvimento das valvas $\mathrm{AV}$ e sinais subseqüentes ${ }^{43}$. O diagnóstico diferencial impõe-se principalmente na EMF direita (quadro I). A EMF esquerda representa uma das etiologias de insuficiência mitral. A diferenciação da fibrose com trombos apicais(p.ex aneurismas de ponta)é facilmente descartada, uma vez que não há acinesia ou discinesia na EMF esquerda. OETE está indicado quando existem dificuldades técnicas ao exame transtorácico e na monitorização transoperatória da ressecção da fibrose e correção dos defeitos valvares por via apical .

\section{Valvopatias, Sopros Cardíacos e Próteses Valvares}

\subsection{Valvas nativas}

A ecocardiografia é um método importante de avaliação dos sopros cardíacos e das valvopatias. A modalidade bidimensional pode demonstrar alterações morfológicas e funcionais da valvas, mas, habitualmente, não se presta para a correta quantificação da gravidade das lesões valvares, exceção feita à estenose mitral. A utilização do Doppler espectral identifica anormalidades dos fluxos, permitindo assim a exata quantificação das estenoses valvares pela determinação dos gradientes e áreas das valvas. Com o emprego do mapeamento do fluxo em cores, torna-se possível identificar e quantificar a gravidade dos jatos regurgitantes. Se o diagnóstico não é elucidado de maneira satisfatória por

\begin{tabular}{|lc|}
\hline \multicolumn{2}{|c|}{$\begin{array}{c}\text { Tabela V - Indicações da ecocardiografia para pacientes adultos } \\
\text { assintomáticos com sopros cardíacos }\end{array}$} \\
\hline Indicação & Classe \\
\hline Sopros sistólico, diastólico ou contínuo & I \\
Sopro associado a palpação e ausculta normais & IIa \\
Sopro associado a ECG e radiografia de tórax normais & IIa \\
$\begin{array}{l}\text { Sopro mesossistólico de grau leve, identificado como } \\
\text { inocente ou funcional por observador experiente }\end{array}$ & IIb \\
$\begin{array}{l}\text { Detecção de regurgitações mitrais ou aórticas silenciosas } \\
\text { em pacientes sem sopros cardíacos, com o intuito de } \\
\text { fazer profilaxia da endocardite infecciosa }\end{array}$ & III \\
\hline
\end{tabular}

\begin{tabular}{|c|c|}
\hline \multicolumn{2}{|c|}{$\begin{array}{c}\text { Tabela VI - Indicações da ecocardiografia para pacientes } \\
\text { sintomáticos com sopros cardíacos }\end{array}$} \\
\hline Indicação & Classe \\
\hline Sintomas ou sinais de ICC, angina ou síncope & I \\
\hline $\begin{array}{l}\text { Sintomas ou sinais de endocardite infecciosa ou } \\
\text { tromboembolismo }\end{array}$ & I \\
\hline $\begin{array}{l}\text { Diferenciação de sintomas ou sinais ocasionados por } \\
\text { doenças cardíacas de extra-cardíacas, não elucidados } \\
\text { com avaliação cardiológica básica }\end{array}$ & IIa \\
\hline $\begin{array}{l}\text { Sintomas ou sinais de doença extracardíaca } \\
\text { associados com sopro mesossistólico "inocente" isolado }\end{array}$ & III \\
\hline
\end{tabular}

\begin{tabular}{|lc|}
\hline \multicolumn{1}{|c|}{ Tabela VII - Indicações da ecocardiografia na estenose mitral (EM) } \\
\hline Indicação & Classe \\
\hline $\begin{array}{l}\text { Diagnóstico, avaliação da gravidade (gradiente médio, } \\
\text { área valvar e pressão arterial pulmonar) e avaliação do } \\
\text { tamanho e função do ventrículo direito }\end{array}$ & I \\
$\begin{array}{l}\text { Avaliação da morfologia valvar para determinar a } \\
\text { possibilidade de tratamento por meio da valvotomia } \\
\text { percutânea com cateter }\end{array}$ & I \\
$\begin{array}{l}\text { Diagnóstico e avaliação de lesão valvar associada } \\
\text { Reavaliação de pacientes sabidamente portadores de EM } \\
\text { que apresentaram alterações dos sinais ou sintomas } \\
\text { Reavaliação da pressão arterial pulmonar em pacientes } \\
\text { assintomáticos, portadores de EM moderada a grave } \\
\begin{array}{l}\text { Reavaliação rotineira de pacientes assintomáticos com EM } \\
\text { de grau discreto e achados clínicos estáveis }\end{array}\end{array}$ & I \\
\hline
\end{tabular}

meio da ecocardiografia transtorácica, o emprego da ecocardiografia transesofágica torna-se uma excelente opção. É necessário saber que mínimas regurgitações valvares "fisiológicas" podem ser detectadas em indivíduos saudáveis, tanto nas valvas do lado direito (mais freqüentes) como nas do lado esquerdo. $\mathrm{Na}$ endocardite infecciosa, os critérios maiores da Duke University incluem uma massa oscilante, abscesso anular ou deiscência de prótese. Nestas situações, por vezes, o estudo transesofágico é necessário para adicionar dados ao exame transtorácico. As duas modalidades de exame (torácico e esofágico) são complementares e se integram na avaliação cardíaca. Uma recente indicação da ECO inclui pacientes em uso de anorexígenos que podem causar valvopatias 


\begin{tabular}{|c|c|}
\hline \multicolumn{2}{|c|}{$\begin{array}{c}\text { Tabela VIII - Indicações da ecocardiografia sob esforço físico na } \\
\text { estenose mitral }\end{array}$} \\
\hline Indicação & Classe \\
\hline $\begin{array}{l}\text { Avaliação da resposta hemodinâmica do gradiente } \\
\text { médio e da pressão arterial pulmonar ao exercício, } \\
\text { quando há discrepância entre os achados clínicos e } \\
\text { hemodinâmicos de repouso }\end{array}$ & Iia \\
\hline
\end{tabular}

\begin{tabular}{|c|c|}
\hline \multicolumn{2}{|c|}{$\begin{array}{l}\text { Tabela IX - Indicações de ecocardiograma transesofágico na } \\
\text { estenose mitral }\end{array}$} \\
\hline Indicação & Classe \\
\hline $\begin{array}{l}\text { Uso na orientação de procedimento intervencionista } \\
\text { (valvotomia por cateter-balão) }\end{array}$ & I \\
\hline $\begin{array}{l}\text { Determinação da presença ou ausência de trombo } \\
\text { atrial esquerdo em candidatos à valvotomia transmitral } \\
\text { percutânea por catéter }\end{array}$ & IIa \\
\hline $\begin{array}{l}\text { Avaliação da morfologia da valva mitral e hemodinâmica } \\
\text { quando os achados transtorácicos são inadequados }\end{array}$ & IIa \\
\hline $\begin{array}{l}\text { Avaliação rotineira da morfologia da valva mitral e } \\
\text { hemodinâmica quando os dados obtidos por meio } \\
\text { do exame transtorácico são satisfatórios }\end{array}$ & III \\
\hline
\end{tabular}

\begin{tabular}{|lc|}
\hline \multicolumn{2}{|l|}{ Tabela X - Indicações da ecocardiografia na insuficiência mitral (IM) } \\
\hline Indicação & Classe \\
\hline $\begin{array}{l}\text { Avaliação inicial da gravidade da IM e função ventricular } \\
\text { esquerda em qualquer paciente com suspeita desta doença }\end{array}$ & I \\
$\begin{array}{l}\text { Determinação do mecanismo da IM } \\
\text { Avaliação anual/semestral da função VE (estimada pela } \\
\text { fração de ejeção ou diâmetro sistólico final do VE) } \\
\text { em pacientes assintomáticos com IM grave }\end{array}$ & I \\
$\begin{array}{l}\text { Avaliação cardíaca após alteração de sintomas } \\
\text { Avaliação cardíaca inicial após implante de prótese ou } \\
\text { cirurgia reparadora (plastia valvar) }\end{array}$ & I \\
$\begin{array}{l}\text { Avaliação rotineira da IM discreta com função/dimensão } \\
\text { normais do VE }\end{array}$ & I \\
\hline
\end{tabular}

As recomendações gerais para a utilização da ECO-D nos portadores de sopro cardíaco, valvopatias, prótese valvares e endocardite infecciosa são as seguintes ${ }^{44-47}$ :

\subsection{Próteses valvares}

Apesar da contínua evolução na fabricação das próteses, mesmo após implante valvar bem sucedido, os pacientes estão sujeitos a complicações como fenômenos embólicos, endocardite infecciosa e processos degenerativos das próteses.

A ecocardiografia, com suas modalidades transtorácica (ETT) e transesofágica (ETE) é um importante método diagnóstico não invasivo das disfunções protéticas. Recomenda-se um ETT basal como padrão para exames evolutivos, a ser realizado entre 3 a 4 semanas após alta hospitalar ${ }^{46}$, tempo necessário para o coração adaptar-se às novas condições hemodinâmicas. Embora não exista um consenso

\begin{tabular}{|c|c|}
\hline \multicolumn{2}{|c|}{$\begin{array}{c}\text { Tabela XI - Indicações da ecocardiografia transesofágica na } \\
\text { insuficiência mitral }\end{array}$} \\
\hline Indicação & Classe \\
\hline $\begin{array}{l}\text { Avaliação transesofágica intra-operatória para } \\
\text { estabelecer as causas anatômicas da IM e } \\
\text { auxiliar no reparo valvar }\end{array}$ & I \\
\hline $\begin{array}{l}\text { Avaliação de pacientes com IM, nos quais o exame } \\
\text { transtorácico mostrou-se insatisfatório para a } \\
\text { determinação da gravidade e/ou do mecanismo da } \\
\text { regurgitação, assim como para a avaliação da função do VE }\end{array}$ & I \\
\hline $\begin{array}{l}\text { Acompanhamento rotineiro ou avaliação de pacientes } \\
\text { com IM em portadores de valva nativa }\end{array}$ & III \\
\hline
\end{tabular}

\begin{tabular}{|c|c|}
\hline \multicolumn{2}{|c|}{$\begin{array}{c}\text { Tabela XII - Indicações da ecocardiografia no prolapso da } \\
\text { valva mitral (PVM) }\end{array}$} \\
\hline Indicação & Classe \\
\hline $\begin{array}{l}\text { Diagnóstico, avaliação da gravidade hemodinâmica } \\
\text { da regurgitação, da morfologia dos folhetos e } \\
\text { compensação ventricular em pacientes } \\
\text { com sinais físicos de PVM }\end{array}$ & I \\
\hline $\begin{array}{l}\text { Exclusão do PVM em pacientes com tal diagnóstico } \\
\text { e sem evidências clinicas que sustentem este diagnóstico }\end{array}$ & I \\
\hline $\begin{array}{l}\text { Exclusão do PVM em pacientes que possuem parentes } \\
\text { sabidamente portadores de doença valvar mixomatosa }\end{array}$ & IIa \\
\hline $\begin{array}{l}\text { Estratificação de risco em pacientes com sinais físicos } \\
\text { ou diagnóstico prévio de PVM }\end{array}$ & Iia \\
\hline $\begin{array}{l}\text { Exclusão do PVM em pacientes com ausência de achados } \\
\text { físicos sugestivos ou uma história familiar positiva }\end{array}$ & III \\
\hline $\begin{array}{l}\text { Repetição rotineira do ecocardiograma em pacientes com } \\
\text { PVM competente ou que apresentam regurgitação de grau } \\
\text { discreto, sem alterações de sintomas ou sinais clínicos }\end{array}$ & III \\
\hline
\end{tabular}

\begin{tabular}{|c|c|}
\hline Tabela XIII - Indicações da ecocardiografia na estenose aórti & (EA) \\
\hline Indicação & Classe \\
\hline Diagnóstico e avaliação da gravidade da EA & $\mathrm{I}$ \\
\hline Avaliação da hemodinâmica, função e/ou tamanho do VE na EA & I \\
\hline $\begin{array}{l}\text { Reavaliação de pacientes com EA já diagnosticada, que } \\
\text { apresentam alterações nos sintomas ou sinais físicos }\end{array}$ & I \\
\hline $\begin{array}{l}\text { Avaliação de alterações da gravidade hemodinâmica } \\
\text { e compensação ventricular, em pacientes com EA já } \\
\text { diagnosticada, durante gravidez }\end{array}$ & $\mathrm{I}$ \\
\hline $\begin{array}{l}\text { Reavaliação de pacientes assintomáticos, portadores } \\
\text { de EA grave }\end{array}$ & I \\
\hline $\begin{array}{l}\text { Reavaliação de pacientes assintomáticos, portadores de } \\
\text { EA de grau discreto a moderado e evidências de disfunção } \\
\text { ou hipertrofia do VE }\end{array}$ & IIa \\
\hline $\begin{array}{l}\text { Reavaliação rotineira de pacientes adultos assintomáticos } \\
\text { com EA de grau discreto, que apresentam sinais físicos } \\
\text { inalterados e função/dimensões normais do VE }\end{array}$ & III \\
\hline $\begin{array}{l}\text { Ecocardiograma de estresse com dobutamina para avaliação } \\
\text { de pacientes com EA com baixo gradiente e disfunção miocárdica }\end{array}$ & $\mathrm{IIb}$ \\
\hline $\begin{array}{l}\text { Ecocardiograma com esforço para avaliação da resposta } \\
\text { hemodinâmica em pacientes sem EA crítica }\end{array}$ & $\mathrm{IIb}$ \\
\hline
\end{tabular}

sobre a periodicidade de ecocardiogramas evolutivos em pacientes sem sintomas ou sinais clínicos de disfunção protética, é recomendado um ETT anual. Na hipótese clínica de disfunção protética, o ETT faz parte dos exames comple- 


\begin{tabular}{|c|c|}
\hline \multicolumn{2}{|c|}{ Tabela XIV - Indicações da ecocardiografia na insuficiência aórtica (IA) } \\
\hline Indicação & Classe \\
\hline Diagnóstico e avaliação da gravidade da IA aguda & I \\
\hline $\begin{array}{l}\text { Diagnóstico da IA crônica em pacientes com } \\
\text { achados físicos duvidosos }\end{array}$ & \\
\hline $\begin{array}{l}\text { Avaliação da etiologia da IA (morfologia valvar e } \\
\text { tamanho da raiz da aorta) }\end{array}$ & I \\
\hline $\begin{array}{l}\text { Avaliação da função sistólica, dimensões e grau } \\
\text { de hipertrofia do VE }\end{array}$ & I \\
\hline Estimativa semi-quantitativa da gravidade da IA & I \\
\hline $\begin{array}{l}\text { Reavaliação de pacientes com IA discreta, moderada ou } \\
\text { grave, que apresentam sintomas novos ou alterados }\end{array}$ & I \\
\hline $\begin{array}{l}\text { Reavaliação da função/dimensões do VE em } \\
\text { assintomáticos com IA grave }\end{array}$ & I \\
\hline $\begin{array}{l}\text { Reavaliação de pacientes assintomáticos com IA, } \\
\text { moderada ou grave e dilatação da raiz da aorta }\end{array}$ & I \\
\hline $\begin{array}{l}\text { Reavaliação anual de pacientes assintomáticos com } \\
\text { IA discreta a moderada, com sinais físicos estáveis e } \\
\text { VE normal ou discretamente aumentado }\end{array}$ & III \\
\hline
\end{tabular}

Tabela XV - Indicações da ecocardiografia na endocardite infecciosa (EI) em valva nativa

\begin{tabular}{ll}
\hline Indicação & Class \\
\hline
\end{tabular}

Deteç̧ão de vegetações; caracterização, quantificação das

I

lesões valvares e avaliação da repercussão funcional

ventricular em pacientes com suspeita clínica de EI *

Detecção de anormalidades associadas

(p.ex: abcessos anulares, fístulas)*

Estudos de reavaliação em casos de endocardite complexa

(p.ex: organismos virulentos, lesão hemodinâmica grave,

envolvimento da valva aórtica, febre ou bacteremia

persistentes, alterações clínicas ou deterioração dos sintomas) *

Avaliação de pacientes com hemoculturas negativas e alta

suspeita clínica de EI*

Avaliação de pacientes com bacteremia não estaficocócica

sem causa conhecida*

Estratificação de risco em pacientes sabidamente

portadores de EI*

Reavaliação rotineira na EI sem complicações durante

antibioticoterapia

Avaliação de febre e sopro inocente em pacientes sem evidências de bacteremia

(*) A ecocardiografia transesofágica pode fornecer informações adicionais àquelas obtidas por meio da ecocardiografia transtorácica.

mentares para avaliação diagnóstica, e poderá posteriormente ser complementado pelo ETE, principalmente se houver suspeita de endocardite infecciosa ou trombose da prótese. As próteses valvares, principalmente as mecânicas, causam reverberações e sombras acústicas, prejudicando freqüentemente uma boa avaliação ecocardiográfica, principalmente pelo ETT. OETE, devido sua proximidade e abordagem posterior do coração, consegue melhor acurácia diagnóstica nas disfunções das próteses valvares. $\mathrm{Na}$ realidade, os ETT e ETE se complementam, sendo sempre aconselhável realizar um ETT completo e cuidadoso antes de indicar o ETE.

\begin{tabular}{|c|c|}
\hline \multicolumn{2}{|c|}{$\begin{array}{c}\text { Tabela XVI - Indicações da ecocardiografia transesofágica em } \\
\text { endocardite infecciosa (EI) }\end{array}$} \\
\hline Indicação & Classe \\
\hline $\begin{array}{l}\text { Avaliação de pacientes com alta probabilidade clínica de } \\
\text { EI em valva nativa ou próteses, e exame transtorácico } \\
\text { inconclusivo (particularmente bacteremia por estafilococcus } \\
\text { ou fungemia sem foco aparente) }\end{array}$ & Classe I \\
\hline $\begin{array}{l}\text { Pesquisa de abscesso paravalvar em valvas nativas ou } \\
\text { próteses (inclusive vazamento paraprotético) } \\
\text { particularmente no envol vimento mitro-aórtico }\end{array}$ & Classe I \\
\hline $\begin{array}{l}\text { Avaliação de pacientes com EI bem documentada por } \\
\text { exame transtorácico, não complicada }\end{array}$ & Classe III \\
\hline
\end{tabular}

\begin{tabular}{|lc|}
\hline \multicolumn{2}{|c|}{ Tabela XVII - Indicações da ecocardiografia nas próteses valvares } \\
\hline Indicação & Classe \\
\hline $\begin{array}{l}\text { Avaliação rotineira evolutiva em pacientes com } \\
\text { prótese sem sinais ou sintomas de disfunção } \\
\text { Avaliação de pacientes com suspeita de disfunção } \\
\text { protética (complementar com eco transesofágico na } \\
\text { suspeita de trombose) ou para diagnóstico } \\
\text { diferencial com disfunção ventricular } \\
\begin{array}{l}\text { Reavaliação de rotina após estudo basal, em pacientes } \\
\text { portadores de prótese, com disfunção ventricular, sem } \\
\text { modificação dos sintomas/sinais clínicos }\end{array}\end{array}$ & I \\
$\begin{array}{l}\text { Realização de ECO transesofágica em pacientes com } \\
\text { diagnóstico de disfunção protética ao ECO-D } \\
\text { transtorácico para confirmação diagnóstica, melhor } \\
\text { quantificação da lesão ou complementação de dados }\end{array}$ & IIa \\
\hline
\end{tabular}

\begin{tabular}{|c|c|}
\hline \multicolumn{2}{|c|}{$\begin{array}{l}\text { Tabela XVIII - Indicações da ecocardiografia na endocardite } \\
\text { infecciosa em pacientes com próteses valvares }\end{array}$} \\
\hline Indicação & Classe \\
\hline $\begin{array}{l}\text { Detecção e caracterização da lesão valvar, avaliação } \\
\text { da severidade hemodinâmica e desempenho ventricular }(*)\end{array}$ & I \\
\hline $\begin{array}{l}\text { Detecção de possíveis complicações como abscessos, } \\
\text { rupturas, fístulas etc. }(*)\end{array}$ & I \\
\hline $\begin{array}{l}\text { Reavaliação nos casos complexos como causados por } \\
\text { organismos virulentos, lesões hemodinâmicas severas, } \\
\text { envolvimento da válvula aórtica, persistência de febre } \\
\text { ou bacteremia, mudanças dos sinais clínicos ou } \\
\text { deterioração dos sintomas }\left(^{*}\right)\end{array}$ & I \\
\hline $\begin{array}{l}\text { Avaliação de suspeita de endocardite em paciente com } \\
\text { culturas negativas }(*)\end{array}$ & I \\
\hline Avaliação de bacteremia de etiologia desconhecida $(*)$ & I \\
\hline $\begin{array}{l}\text { Avaliação de febre persistente sem evidências de } \\
\text { bacteremia ou novos sopros }(*)\end{array}$ & IIa \\
\hline $\begin{array}{l}\text { Avaliação de rotina durante o tratamento de endocardite } \\
\text { não complicada }(*)\end{array}$ & IIb \\
\hline $\begin{array}{l}\text { Avaliação de febre transitória sem evidências de bacteremia } \\
\text { ou novo sopro }(*)\end{array}$ & III \\
\hline
\end{tabular}

\section{Avaliação de Dor Torácica}

A causa mais comum de dor torácica de etiologia cardíaca é a isquemia miocárdica por coronariopatia, seguida 


\begin{tabular}{|c|c|}
\hline \multicolumn{2}{|l|}{$\begin{array}{c}\text { Tabela XIX- Indicações da ecocardiografia em pacientes com } \\
\text { dor torácica }{ }^{1-3}\end{array}$} \\
\hline Indicação & Classe \\
\hline $\begin{array}{l}\text { Presença de patologias cardíacas não isquêmicas } \\
\text { (pericardite, valvopatias, miocardiopatias) }\end{array}$ & I \\
\hline Suspeita de isquemia miocárdica ou infarto atual & I \\
\hline Pacientes com isquemia ou infarto pregresso & I \\
\hline Suspeita de dissecção de aorta & I \\
\hline Diferenciação de doenças não cardíacas como embolia pulmonar & $\mathrm{IIb}$ \\
\hline $\begin{array}{l}\text { Pacientes com instabilidade hemodinâmica } \\
\text { Pacientes do sexo feminino com teste ergométrico }\end{array}$ & I \\
\hline $\begin{array}{l}\text { positivo e/ou antecedentes familiares para coronariopatia } \\
\text { e/ou bloqueio de ramo esquerdo }\end{array}$ & $\mathrm{IIb}$ \\
\hline
\end{tabular}

de pericardite, dissecção de aorta, estenose valvar aórtica, prolapso valvar mitral e miocardiopatia hipertrófica. Causas extra-cardíacas incluem tromboembolismo pulmonar, doenças do esôfago, osteoneuropatias, etc. A ECO-D pode confirmar ou afastar alterações segmentares da contratilidade que sugerem, no momento da dor, a presença de isquemia miocárdica, infarto do miocárdio atual ou mesmo infarto pregresso. Se a dor torácica persistir, apesar do tratamento, e a função contrátil for normal, dificilmente será por infarto do miocárdio. Se a alteração segmentar da contratilidade persistir, mesmo após o desaparecimento da dor, pode ser infarto do miocárdio ou angina instável com miocárdio atordoado. O ECO pode ser feito sempre que possível, na sala de emergência, durante o episódio de dor torácica. $\mathrm{O}$ valor de novos aparelhos portáteis nestas circunstâncias está sendo estudado.

\section{Doença Arterial Coronariana}

\subsection{Síndromes isquêmicas agudas}

4.1.1 Infarto agudo do miocárdio - OECO-D auxilia no diagnóstico de isquemia aguda (infarto do miocárdio ou angina instável) quando a historia clinica e o eletrocardiograma são diagnósticos ou não. As alterações segmentares da contratilidade podem estar presentes no momento da dor e após seu desaparecimento, significando isquemia transitória na fase aguda, miocárdio hibernante ou fibrose na fase crônica. Nos pacientes com dor prolongada, a presença de alteração segmentar da contratilidade sugere infarto, mas na presença de função contrátil normal, a probabilidade de infarto é remota. Como a isquemia aguda e o infarto agudo evidenciam alteração segmentar da contratilidade, não podem ser separados pelo ECO-D isoladamente. Após o período agudo, com a reversão da alteração segmentar da contratilidade demonstrada pelo ECO-D pode-se diferenciar a angina instável do infarto agudo, em que permanece inalterado. Outra aplicação da ECO-D é na avaliação da função contrátil do ventrículo esquerdo e das complicações pósinfarto como derrame pericárdico, refluxo valvar mitral, aneurisma, trombose intracavitária, infarto do ventrículo di-

\begin{tabular}{|c|c|}
\hline \multicolumn{2}{|l|}{$\begin{array}{c}\text { Tabela XX - Indicações da ecocardiografia no infarto } \\
\text { agudo do miocárdio }\end{array}$} \\
\hline Indicação & Classe \\
\hline Auxílio diagnóstico com suspeita clínica e ECG inconclusivo & I \\
\hline Análise da função contrátil global dos ventrículos & I \\
\hline $\begin{array}{l}\text { Análise da localização e extensão da área de alteração } \\
\text { contrátil segmentar, com infarto já diagnosticado por } \\
\text { ECG e enzimas }\end{array}$ & I \\
\hline Deteç̧ão de trombos intracavitários & I \\
\hline $\begin{array}{l}\text { Avaliação de complicações mecânicas (aneurisma de VE, } \\
\text { rotura de parede livre, septo ventricular ou músculo } \\
\text { papilar, derrame pericárdico) }\end{array}$ & I \\
\hline $\begin{array}{l}\text { No infarto inferior, avaliação da possibilidade do } \\
\text { envolvimento do ventrículo direito e do músculo papilar } \\
\text { póstero-medial }\end{array}$ & I \\
\hline $\begin{array}{l}\text { Pesquisa de viabilidade miocárdica com potencial } \\
\text { indicação cirúrgica }\end{array}$ & I \\
\hline $\begin{array}{l}\text { Avaliação da estratificação de risco pela ecocardiografia } \\
\text { convencional, ou com ecocardiografia de estresse na } \\
\text { detecção de isquemia residual }\end{array}$ & $\mathrm{IIb}$ \\
\hline Auxílio na orientação terapêutica & IIa \\
\hline Auxílio na avaliação prognóstica pré-alta hospitalar & ІІа \\
\hline
\end{tabular}

\begin{tabular}{|lc|}
\hline \multicolumn{1}{|c|}{$\begin{array}{c}\text { Tabela XXI - Indicações de ecocardiografia na avaliação pós- } \\
\text { operatória de cirurgia cardíaca no infarto do miocárdio }\end{array}$} \\
\hline Indicação & Classe \\
\hline $\begin{array}{l}\text { Avaliação da função contrátil global e segmentar do VE } \\
\text { Avaliação da correção das complicações mecânicas do infarto }\end{array}$ & I \\
$\begin{array}{l}\text { Avaliação de tamponamento na instabilidade } \\
\text { hemodinâmica (eco transtorácico ou transesofágico) } \\
\text { Avaliação de reestenose pós-revascularizaçao nos } \\
\text { pacientes com sintomas atípicos (eco sob estresse) }\end{array}$ & I \\
$\begin{array}{l}\text { Avaliação de reestenose pós-revascularização nos pacientes } \\
\text { com sintomas típicos (eco sob estresse) }\end{array}$ & IIa \\
$\begin{array}{l}\text { Avaliação de viabilidade nos candidatos a reoperação } \\
\text { (eco sob estresse) }\end{array}$ & I \\
\hline
\end{tabular}

reito, comunicação interventricular, rotura de papilar e rotura de parede livre do ventrículo esquerdo. Na análise da estratificação de risco pelo ecocardiograma convencional, pode-se afirmar que quanto menor a área de isquemia ou infarto, quanto mais precocemente houver regressão da alteração segmentar da contratilidade e menores as complicações pós-infarto, melhor será o prognóstico. Pode-se usar a ECO-D com contraste para a análise da perfusão miocárdica nos segmentos com contratilidade alterada pós-infarto na beira do leito, para previsão de recuperação contrátil. Se a função contrátil global do ventrículo esquerdo estiver preservada e a função diastólica discretamente alterada ou normal, o prognóstico pós-infarto será favorável. Na orientação terapêutica pós-infarto, a ECO-D auxilia na análise da função contrátil global e segmentar dos ventrículos. A estratificação de risco pode ser feita com o ecocardiograma de estresse com esforço ou dobutamina, para avaliar a necessidade do estudo hemodinâmico mais precoce ou avaliar a repercussão funcional da obstrução coronariana já conheci- 
da. Na análise da viabilidade miocárdica, para definir a eficácia de uma revascularização por angioplastia ou cirúrgica para uma área acinética, o ecocardiograma pode ser associado ao contraste com microbolhas e/ou com dobutamina. A reavaliação da função contrátil global e segmentar também auxilia na orientação terapêutica precoce e tardia da revascularização. Na avaliação prognóstica na pré-alta hospitalar, se o paciente já fez estudo hemodinâmico com ou sem revascularizaçao por angioplastia, podem restar obstruções em outras artérias que não a responsável pelo infarto e nesse caso a ecocardiografia de estresse está indicada para avaliar a repercussão funcional das outras obstruções.

4.1.2 Angina instável - $O$ quadro da figura 1 ilustra a aplicação da ECO-D convencional na avaliação de pacientes com dor torácica aguda de diferentes naturezas, incluindo as síndromes coronarianas agudas.

A realização da ECO-D em pacientes com angina instável (AI) permite avaliar se há comprometimento contrátil segmentar, compatível com isquemia, quando o exame é realizado em vigência da dor ${ }^{48}$. Pacientes com AI podem apresentar função ventricular normal fora do episódio doloroso, exceto quando tenha ocorrido infarto do miocárdio prévio. O estudo da função ventricular global pelo ECO-D também é útil, já que a fração de ejeção diminuída aumenta significativamente o risco na evolução ${ }^{49}$. Pacientes com AI de baixo risco para morte ou infarto agudo, evoluindo sem recidiva de dor por, pelo menos, $24 \mathrm{~h}$ e pacientes com risco intermediário controlados por tratamento clínico por, pelo menos, $72 \mathrm{~h}$, podem ser candidatos a estratificação não invasiva para detecção de isquemia, como teste ergométrico e ecocardiograma sob estresse físico ou farmacológico, pos-

\begin{tabular}{|c|c|}
\hline \multicolumn{2}{|c|}{$\begin{array}{c}\text { Tabela XXII - Indicações de ecocardiografia em pacientes com } \\
\text { angina instável (AI) }\end{array}$} \\
\hline Indicação & Classe \\
\hline $\begin{array}{l}\text { Exame durante a dor persistente supostamente isquêmica, } \\
\text { porém com ECG não conclusivo }\end{array}$ & I \\
\hline AI com instabilidade hemodinâmica & I \\
\hline $\begin{array}{l}\text { Suspeita de infarto não avaliada adequadamente por } \\
\text { métodos convencionais }\end{array}$ & I \\
\hline $\begin{array}{l}\text { Avaliação da função ventricular em pacientes com } \\
\text { AI de risco intermediário ou alto não submetidos à } \\
\text { ventriculografia }\end{array}$ & IIa \\
\hline $\begin{array}{l}\text { Ecocardiograma sob estresse, intra-hospitalar ou } \\
\text { precocemente após alta, em pacientes não submetidos } \\
\text { a estudo angiográfico e com "possível isquemia" ou com } \\
\text { AI com risco baixo ou intermediário controlada clinicamente }\end{array}$ & I \\
\hline $\begin{array}{l}\text { Ecocardiograma sob estresse para avaliar significado } \\
\text { funcional de obstrução coronária moderada à angiografia, } \\
\text { desde que o resultado interfira na conduta }\end{array}$ & IIa \\
\hline Ecocardiograma sob estresse em AI de alto risco & III \\
\hline
\end{tabular}

sibilitando diagnóstico mais preciso e alta precoce ${ }^{50}$. Pacientes com diagnóstico de AI de alto risco, ou com recidiva dos sintomas mesmo sob tratamento, são candidatos ao estudo angiográfico. A realização da ECO-D para avaliação da função ventricular pode dispensar o uso da ventriculografia em situações em que haja alguma limitação para a realização do estudo angiográfico. Pacientes que não apresentam quadro clínico típico, sem alterações eletrocardiográficas ou elevação de marcadores de necrose miocárdica na evolução, têm diagnóstico definido como "possível isquemia". A estratificação de risco pela ECO pode ser realizado

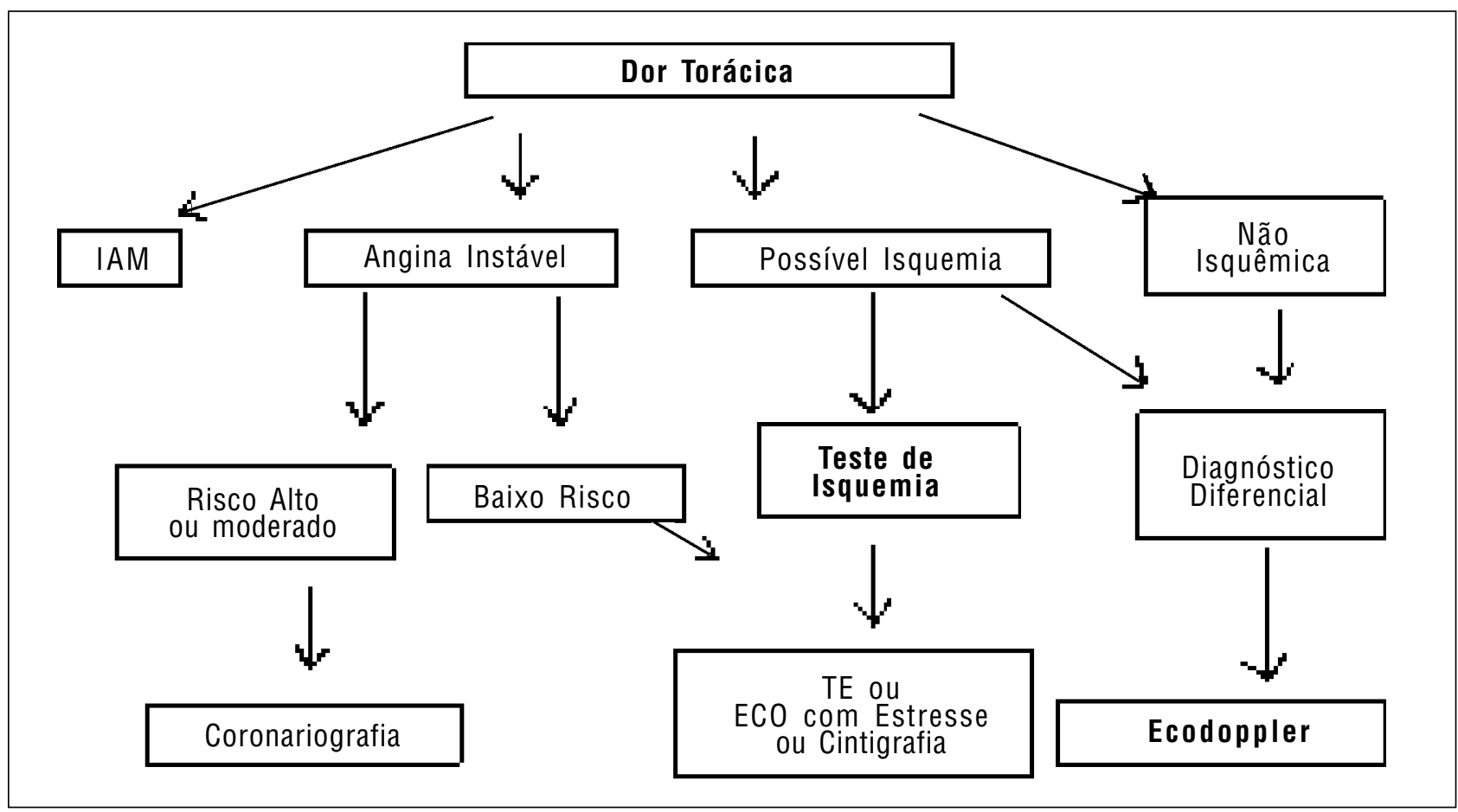

Fig. 1 - Classificação inicial dos pacientes com dor torácica e aplicação da ecocardiografia. 
com esforço físico ou sob efeitos de fármacos indutores de isquemia, como a dobutamina e o dipiridamol associados à atropina. O ecocardiograma com esforço é opção quando o ECG não é adequado para a identificação de isquemia durante o teste ergométrico. Além da presença de isquemia, a ECO sob estresse permite conhecer a extensão de segmentos sob risco. A isquemia desencadeada com freqüência cardíaca abaixo de 120 bpm ou dose baixa de fármacos indica pior prognóstico.

\subsection{Insuficiência coronariana crônica}

4.2.1 Uso da ecocardiografia sob estresse na doença arterial coronariana crônica - A ecocardiografia sob estresse (ECO-estresse) é um método não invasivo estabelecido para avaliação de pacientes com doença arterial coronariana (DAC) obstrutiva suspeita ou conhecida, exercendo um importante papel na determinação do seu diagnóstico e prognóstico, na avaliação do impacto de terapias de revascularização, na detecção de viabilidade miocárdica e no auxílio às decisões terapêuticas. $\mathrm{O}$ estresse cardiovascular causa isquemia miocárdica em regiões supridas por uma artéria com grau significativo de estenose, e este fenômeno é manifestado por alteração transitória da contração segmentar, passível de ser detectado pela ecocardiografia bidimensional, com avaliação de todos os segmentos miocárdicos das diversas paredes do ventrículo esquerdo. Os métodos disponíveis para a indução do estresse são o esforço físico (esteira ou bicicleta ergométrica), a estimulação atrial transesofágica, o uso de drogas vasodilatadoras (dipiridamol e adenosina) ou de estimulantes adrenérgicos (dobutamina). A ECO-estresse apresenta boa acurácia para deteç̧ão de DAC significativa em pacientes com probabilidade pré-teste intermediária ou alta, com maior sensibilidade e especifici-

\begin{tabular}{|c|c|}
\hline \multicolumn{2}{|c|}{$\begin{array}{c}\text { Tabela XXIII - Indicações gerais da ecocardiografia sob estresse no } \\
\text { diagnóstico e prognóstico da DAC crônica }\end{array}$} \\
\hline Indicação & Classe \\
\hline $\begin{array}{l}\text { Avaliação de isquemia miocárdica em indivíduos } \\
\text { sintomáticos } *\end{array}$ & I \\
\hline $\begin{array}{l}\text { Avaliação de isquemia miocárdica em indivíduos } \\
\text { assintomáticos com teste-ergométrico positivo ou duvidoso* }\end{array}$ & IIa \\
\hline $\begin{array}{l}\text { Avaliação de isquemia miocárdica em indivíduos com } \\
\text { bloqueio de ramo esquerdo ou alterações que impeçam uma } \\
\text { adequada análise eletrocardiográfica de isquemia (alterações } \\
\text { ST-T repouso, digital, HVE, etc)* }\end{array}$ & I \\
\hline $\begin{array}{l}\text { Diagnóstico de isquemia miocárdica em pacientes } \\
\text { selecionados com probabilidade pré-teste de grau } \\
\text { intermediário ou alto para DAC** }\end{array}$ & $\mathrm{IIb}$ \\
\hline $\begin{array}{l}\text { Avaliação pré-operatória de cirurgia não-cardíaca de } \\
\text { pacientes com DAC que não podem exercitar-se\# }\end{array}$ & I \\
\hline $\begin{array}{l}\text { Avaliação da função ventricular esquerda global } \\
\text { com exercício* }\end{array}$ & $\mathrm{IIb}$ \\
\hline $\begin{array}{l}\text { Avaliação inicial de indivíduos assintomáticos com baixa } \\
\text { probabilidade de DAC }\end{array}$ & III \\
\hline $\begin{array}{l}\text { Reavaliação periódica de rotina de pacientes estáveis sem } \\
\text { mudança na terapia }\end{array}$ & III \\
\hline $\begin{array}{l}\text { Exame para substituição rotineira do teste ergométrico em } \\
\text { pacientes nos quais a análise eletrocardiográfica é adequada }\end{array}$ & III \\
\hline $\begin{array}{l}\text { * Ecocardiografia sob estresse físico ou farmacológico. } \\
\text { \# Ecocardiografia sob estresse farmacológico. }\end{array}$ & \\
\hline
\end{tabular}

dade para o diagnóstico de DAC em relação ao teste ergométrico, além do valor adicional na localização e quantificação da isquemia miocárdica ${ }^{51}$. A acurácia da ECO-estresse pela dobutamina é semelhante aquela pelo esforço (83 e $85 \%$, respectivamente), e um pouco menor com dipirida$\mathrm{mol}^{52}$. A adição de atropina a ECO-estresse farmacológica aumenta a acurácia e diminui a porcentagem de testes ineficazes, especialmente em pacientes sob uso de betabloqueador. A sensibilidade global é maior em pacientes com doença multiarterial do que em uniarteriais, em pacientes com infarto miocárdico prévio e naqueles com lesões $>70 \%$ de obstrução ${ }^{51,52}$. É importante saber a probabilidade pré-teste da doença a ser avaliada, considerando-se história clínica, fatores de risco, exame físico e sintomas, especialmente a dor torácica. Assim, se um paciente assintomático apresenta um teste ergométrico com possível resultado falso-positivo, uma ECO-estresse negativa pode ser útil na diminuição da probabilidade de DAC.

A escolha do tipo de estresse deve basear-se no objetivo do exame e nas condições clínicas associadas, considerando-se as contra-indicações específicas para cada modalidade ${ }^{52}$. O teste com esforço físico está indicado em pacientes com capacidade de exercício preservada, aptos a realizar o teste ergométrico máximo e eficaz, ou para avaliação de angina de esforço. Pacientes com quadro clínico de insuficiência coronariana e impossibilitados de realizar esforço físico por razões ortopédicas, pulmonares, neurológicas ou vasculares devem ser submetidos à ecocardiografia com uso de estresse farmacológico, assim como pacientes com indicação de pesquisa de viabilidade miocárdica (com utilização da dobutamina).

Em pacientes com DAC crônica, assim como com a função ventricular esquerda em repouso, a isquemia miocárdica induzida pela ECO-estresse também tem valor prognóstico ${ }^{53}$. A presença de resultado negativo está associada a baixo risco de eventos cardiovasculares durante o acompanhamento, ao contrário do resultado positivo. Em pacientes com infarto miocárdico prévio, a ecocardiografia sob estresse pode ser útil na avaliação da presença, distribuição e se-

\begin{tabular}{|c|c|}
\hline \multicolumn{2}{|c|}{$\begin{array}{c}\text { Tabela XXIV - Indicações da ecocardiografia sob estresse na } \\
\text { avaliação de revascularização cirúrgica ou percutânea em } \\
\text { pacientes com DAC crônica }\end{array}$} \\
\hline Indicação & Classe \\
\hline $\begin{array}{l}\text { Avaliação do significado funcional de lesões coronárias } \\
\text { no planejamento de angioplastia transluminal percutânea } \\
\text { ou cirurgia de revascularização* }\end{array}$ & I \\
\hline $\begin{array}{l}\text { Avaliação de viabilidade miocárdica (miocárdio hibernado) } \\
\text { para planejamento de revascularização\# }\end{array}$ & I \\
\hline $\begin{array}{l}\text { Avaliação de reestenose após revascularização em pacientes } \\
\text { com recorrência de sintomas atípicos* }\end{array}$ & I \\
\hline $\begin{array}{l}\text { Avaliação de reestenose após revascularização em pacientes } \\
\text { com recorrência de sintomas típicos* }\end{array}$ & IIa \\
\hline $\begin{array}{l}\text { Avaliação de rotina em pacientes assintomáticos após } \\
\text { revascularização cirúrgica ou percutânea }\end{array}$ & III \\
\hline $\begin{array}{l}\text { * Ecocardiografia sob estresse físico ou farmacológico. } \\
\text { \# Ecocardiografia sob estresse pela dobutamina. }\end{array}$ & \\
\hline
\end{tabular}


veridade da isquemia miocárdica, com importantes implicações prognósticas ${ }^{54}$. A ECO-estresse pela dobutamina é útil também na estratificação de risco pré-operatório de pacientes com DAC, sobretudo em cirurgias vasculares de grande porte ${ }^{55}$.

A avaliação da reserva coronária pela ECO-estresse é útil para demonstrar o significado funcional de uma determinada obstrução coronária, a exemplo da indicação de angioplastia em pacientes com estenoses coronarianas de grau moderado ou na presença de múltiplas lesões. Além disto, a eco-estresse pode ser utilizada na avaliação de pacientes sintomáticos para detecção de reestenose após angioplastia ou obstrução do enxerto ou novas lesões após cirurgia de revascularização. Outra importante indicação da ecocardiografia sob estresse é a pesquisa de viabilidade miocárdica em pacientes com DAC crônica, em que a depressão da função contrátil miocárdica pode estar relacionada à necrose miocárdica ou por miocárdio hibernado, com importante implicações prognósticas ${ }^{56}$.

4.2.2 Utilização do contraste ecocardiográfico de microbolhas - $\mathrm{O}$ uso de contraste ecocardiográfico à base de microbolhas possibilita melhor definição dos bordos endocárdicos, permitindo avaliação mais adequada do espessamento miocárdico parietal e da função contrátil global e segmentar do ventrículo esquerdo, em repouso e sob estresse ${ }^{57}$.É útil e seguro nos pacientes com indicação de ecoestresse farmacológico, quando têm imagens subótimas em repouso, para melhorar delineamento de bordos ${ }^{58}$. O contraste pode também realçar o efeito Doppler no estudo de jatos regurgitantes ou estenoses valvares. Embora estudos experimentais em animais e em humanos tenham demonstrado a possibilidade do uso do contraste na avaliação da perfusão miocárdica ${ }^{59,60}$, seu uso na prática médica ainda está restrito a centros terciários, necessitando ainda de padronização da técnica.

4.2.3 Visibilização das artérias coronárias e avaliação da reserva de fluxo coronariano - A ecocardiografia transesofágica possibilita a visibilização da porção proximal das artérias coronárias. A análise das velocidades de fluxo no terço inicial da artéria coronária descendente anterior, associada ao uso de vasodilatadores (adenosina ou dipiri-

\begin{tabular}{|lc|}
\hline \multicolumn{2}{|c|}{$\begin{array}{c}\text { Tabela XXV - Indicações da ecocardiografia com contraste } \\
\text { ecocardiográfico de microbolhas }\end{array}$} \\
\hline Indicação & Classe \\
\hline $\begin{array}{l}\text { Avaliação da função ventricular esquerda global e } \\
\text { segmentar em pacientes com imagens subótimas } \\
\text { Melhora do sinal Doppler em pacientes com imagem subótima }\end{array}$ & I \\
$\begin{array}{l}\text { Delineamento de bordos endocárdicos durante a ecocardiografia } \\
\text { sob estresse em pacientes com imagens subótimas em repouso }\end{array}$ & I \\
$\begin{array}{l}\text { Uso rotineiro do contraste ecocardiográfico em todos os pacientes } \\
\text { Delineamento de bordos endocárdicos durante a ecocardiografia } \\
\text { sob estresse em pacientes com janela acústica adequada }\end{array}$ & III \\
Avaliação de perfusão miocárdica & III \\
\hline
\end{tabular}

damol), permite avaliação não invasiva da reserva de fluxo coronariano, útil na determinação do significado funcional de estenose nesta artéria ou no estudo das alterações da microcirculação coronariana ${ }^{61}$. O desenvolvimento tecnológico tem permitido a visibilização da artéria coronária descendente anterior em sua porção média e distal pela ecocardiografia transtorácica, inclusive com medida da reserva de fluxo coronariano ${ }^{62}$.

A ecocardiografia de contraste com perfusão em tempo real associada à quantificação do fluxo miocárdico regional é uma técnica recente que permite a quantificação da reserva de fluxo coronariano ${ }^{63}$. Entretanto, a avaliação das artérias coronárias e a quantificação da reserva de fluxo pela ecocardiografia permanecem limitadas a pequenos estudos, não havendo consenso atual para seu uso clínico.

\section{Hipertensão Arterial Sistêmica}

Os efeitos estruturais e funcionais da hipertensão arterial sistêmica(HAS) sobre o miocárdio podem ser avaliados pela ECO-D, não só sobre a função sistólica ou diastólica, mas sobretudo em relação ao grau e formas de hipertrofia ventricular esquerda (HVE). O exame permite identificar e quantificar a hipertrofia miocárdica, com base na medida da espessura das paredes ventriculares e da massa do VE, bem como caracterizar o padrão geométrico ventricular, a partir da relação entre a massa ventricular e a espessura relativa das paredes. São caracterizados três tipos de padrão geométrico anormais do VE: a) hipertrofia concêntrica (aumento da massa do VE associada a aumento da espessura relativa da parede ventricular); b) hipertrofia excêntrica (aumento da massa do VE em associação à espessura relativa de parede ventricular normal) ec) remodelamento concêntrico (massa ventricular esquerda normal associada a aumento da espessura relativa da parede ventricular). Este último padrão se relaciona a pior prognóstico ${ }^{64}$. A avaliação da hipertrofia tem relevância clínica, pois representa fator de risco independente de morbimortalidade cardíaca ${ }^{64}$. Estes aspectos devem ser valorizados ao se decidir sobre início de tratamento em pacientes com HAS limítrofe. Embora esteja documentada a regressão da

\begin{tabular}{|c|c|}
\hline \multicolumn{2}{|c|}{$\begin{array}{c}\text { Tabela XXVI - Indicações da ecocardiografia na hipertensão } \\
\text { arterial sistêmica }\end{array}$} \\
\hline Indicação & Classe \\
\hline $\begin{array}{l}\text { Necessidade de avaliação da função ventricular ou do } \\
\text { padrão de HVE para orientação terapêutica }\end{array}$ & I \\
\hline $\begin{array}{l}\text { Acompanhamento de dilatação ou disfunção VE já } \\
\text { documentada na vigência de alteração no quadro } \\
\text { clínico para orientação terapêutica }\end{array}$ & I \\
\hline $\begin{array}{l}\text { Detecção ou avaliação da repercussão funcional de doença } \\
\text { coronária associada por meio de ecocardiografia de estresse }\end{array}$ & I \\
\hline $\begin{array}{l}\text { Avaliação de HVE em paciente com HAS limítrofe, sem } \\
\text { alteração no ECG para orientar tratamento }\end{array}$ & IIa \\
\hline $\begin{array}{l}\text { Diagnóstico de disfunção diastólica associada ou não à } \\
\text { disfunção sistólica }\end{array}$ & IIa \\
\hline $\begin{array}{l}\text { Estratificação de risco para avaliação prognóstica baseada } \\
\text { na função do VE }\end{array}$ & IIa \\
\hline
\end{tabular}


HVE induzida pelo tratamento, não há consenso sobre o valor de exames periódicos para o acompanhamento da função ventricular ou da massa miocárdica, particularmente em pacientes assintomáticos. A presença de disfunção diastólica, de alterações valvares degenerativas associadas ou de doença coronária podem ser avaliadas, respectivamente pela ECOD ou pela ECO sob estresse.

\section{Doenças Cardioembólicas}

Este termo engloba os processos embólicos que acometem o encéfalo (acidente vascular encefálico: AVE) e a circulação periférica (obstrução arterial aguda). Embora o tromboembolismo pulmonar constitua entidade individualizada, também merece investigação da fonte embolígena, e será discutido em outro capítulo. OAVE de origem embólica oscila em torno de $20 \%$, causado por fibrilação atrial não valvar, cardiopatia isquêmica, aneurisma ventricular, miocardiopatia dilatada, doença valvar reumática, dentre outros. Quando ocorre AVE na ausência de doença vascular cerebral demonstrável, é imprescindível a pesquisa de fonte embólica cardíaca ou extracardíaca (aorta), quer seja direta (trombos, vegetações, tumores) ou indiretas (anormalidades estruturais potencialmente embolígenas: aneurismas, miocardiopatias, forâmen oval patente, etc). A existência de múltiplos eventos acometendo diferentes territórios vasculares, bem como a oclusão aguda de um vaso periférico com a artéria femoral ou renal deve levantar a suspeita de embolia. Além do ecocardiograma transtorácico, pode-se contar com a ECO transesofágica, que é mais sensível e específica, sobretudo na detecção de trombos em átrio esquerdo (particularmente no apêndice atrial esquerdo), de contraste ecográfico espontâneo (marcador de estase sanguínea e precursor de trombos), de vegetações endocárdicas ocultas, de tumores intracardíacos embolígenos (mixomas e fibroelastomas), de aneurismas do septo interatrial, fôramen oval patente (embolia paradoxal) e de ateromas aórticos com

\begin{tabular}{|c|c|}
\hline \multicolumn{2}{|c|}{$\begin{array}{l}\text { Tabela XXVII - Indicações do ecocardiograma* em pacientes com } \\
\text { AVE ou outros eventos vasculares obstrutivos periféricos }{ }^{1-3}\end{array}$} \\
\hline Indicação & Classe \\
\hline $\begin{array}{l}\text { Oclusão aguda, em qualquer idade, de grande artéria } \\
\text { central ou periférica }\end{array}$ & I \\
\hline Paciente jovem ( $<45$ anos) com evento cérebro-vascular agudo & I \\
\hline $\begin{array}{l}\text { Paciente acima de } 45 \text { anos com evento neurológico sem } \\
\text { evidência de vasculopatia cerebral }\end{array}$ & I \\
\hline $\begin{array}{l}\text { AVE com vasculopatia cerebral pré-existente, com suspeita } \\
\text { de embolia }\end{array}$ & I \\
\hline Orientação terapêutica para o uso de anticoagulação & IIa \\
\hline $\begin{array}{l}\text { Evento neurológico agudo sobre doença cerebral } \\
\text { pré-existente, com gravidade suficiente para ser a causa } \\
\text { exclusiva do processo }\end{array}$ & IIb \\
\hline $\begin{array}{l}\text { Pacientes com AVE nos quais o resultado da ECO-D não } \\
\text { iria alterar o diagnóstico ou a conduta terapêutica }\end{array}$ & II \\
\hline $\begin{array}{l}\text { * A ecocardiografia transesofágica pode fornecer informações adi } \\
\text { las obtidas por meio da ecocardiografia transtorácica. }\end{array}$ & is àque- \\
\hline
\end{tabular}

"debris" móveis (placas complexas,rotas e pedunculadas, com trombose recente). Essas condições podem passar despercebidas ao exame transtorácico, ou serem exclusivamente detectadas ao exame transesofágico, que tem maior impacto diagnóstico na pesquisa de trombos no apêndice atrial, pequenas vegetações ou trombos em próteses valvares, forame oval patente, aneurisma do septo interatrial e focos embolígenos da aorta torácica (placas de ateroma móveis ou "debris"). A pesquisa de forame oval patente necessita da ECO transesofágica associada ao uso de contraste com salina agitada e manobra de Valsalva. Essas medidas podem reduzir o número de AVE criptogênicos, transformando-os em cardioembólicos, sobretudo em pacientes jovens. Outros aspectos da fibrilação atrial são discutidos em capítulo especial.

\section{Hipertensão Pulmonar,Tromboembolismo Pulmonar e Doenças Pulmonares}

A ECO-D desempenha papel importante na definição da causa dos sintomas na suspeita de doenças pulmonares (DP), já que a dispnéia pode ter origem pulmonar ou cardíaca, além de avaliar a repercussão cardíaca de pneumopatias primárias. Nos pneumopatas, a janela paraesternal pode ser limitada pela hipersinsuflação pulmonar, que prejudica a transmissão do ultra-som. A despeito das dificuldades téc-

\begin{tabular}{|c|c|}
\hline \multicolumn{2}{|c|}{$\begin{array}{c}\text { Tabela XXVIII - Indicações da ecocardiografia nas doenças } \\
\text { pulmonares e tromboembolismo pulmonar }\end{array}$} \\
\hline Indicação & Classe \\
\hline Suspeita de hipertensão arterial pulmonar & I \\
\hline $\begin{array}{l}\text { Embolia pulmonar e suspeita de coágulos no interior } \\
\text { do átrio ou ventrículo direitos ou da artéria pulmonar } \\
\text { e seus principais ramos* }\end{array}$ & I \\
\hline $\begin{array}{l}\text { Diferenciação entre etiologia cardíaca e não cardíaca da } \\
\text { dispnéia, nos quais os achados clínicos e laboratoriais } \\
\text { são ambíguos* }\end{array}$ & I \\
\hline $\begin{array}{l}\text { Pesquisa de cianose de causa não esclarecida: deteç̧ão } \\
\text { de "shunt" da direita para a esquerda ao nível do forâmen } \\
\text { oval, canal arterial, defeitos septais etc.; diagnóstico de } \\
\text { fistula pulmonar na síndrome hepato-renal ou em outras } \\
\text { situações acompanhadas de hipertensão do sistema porta * \# }\end{array}$ & I \\
\hline $\begin{array}{l}\text { Acompanhamento evolutivo das pressões da AP em } \\
\text { portadores de HP submetidos a algum tipo de tratamento }\end{array}$ & I \\
\hline $\begin{array}{l}\text { Doença pulmonar na qual se suspeita de envolvimento } \\
\text { cardíaco ("cor pulmonale") }\end{array}$ & I \\
\hline $\begin{array}{l}\text { Avaliação do comportamento das pressões da AP durante } \\
\text { o exercício ao eco de esforço }\end{array}$ & IIa \\
\hline $\begin{array}{l}\text { Avaliação de candidatos a transplante pulmonar ou a outros } \\
\text { procedimentos para doença pulmonar avançada * }\end{array}$ & IIa \\
\hline $\begin{array}{l}\text { Avaliação da função do VD (sistólica e diastólica) e da } \\
\text { massa ventricular direita }\end{array}$ & IIa \\
\hline $\begin{array}{l}\text { Doença pulmonar sem dados clínicos que possam sugerir } \\
\text { o envolvimento cardíaco }\end{array}$ & III \\
\hline $\begin{array}{l}\text { Estudos para reavaliação da função do VD em portadores } \\
\text { de DPOC sem mudanças do quadro clínico }\end{array}$ & III \\
\hline $\begin{array}{l}\text { * o estudo transesofágico está indicado quando o exame trans } \\
\text { ficiente para o diagnóstico. } \\
\# \text { o uso de ecocardiografia com contraste salino pode ser nec }\end{array}$ & insu- \\
\hline
\end{tabular}


nicas impostas pela doença pulmonar para avaliação ecocardiográfica, o exame pode dar informações importantes em boa parte dos pacientes. Uma alternativa é a obtenção de imagens por via subcostal. Casos especiais necessitam de estudo transesofágico.

Há certas limitações na avaliação funcional do ventrículo direito (VD), devido à sua conformação geométrica peculiar. A dificuldade no uso de métodos quantitativos no VD impõe o recurso da avaliação subjetiva desta câmara na prática. Nos casos crônicos ("cor pulmonale" crônico) causados por doença pulmonar obstrutiva crônica (DPOC) ou fibrose pulmonar, a repercussão da HP pode determinar dilatação e hipocinesia do VE, com alterações do formato e mobilidade do septo interventricular. São freqüentes os refluxos valvares tricúspide e pulmonar, tanto no indivíduo normal como no portador de hipertensão arterial pulmonar, atingindo aproximadamente $70 \%$ da população ${ }^{65}$. A gravidade da hipertensão arterial pulmonar (HP), uma freqüente complicação da DP, pode ser estimada quanto à sua severidade por meio da ECO-D. O método mais comum consiste na determinação da pressão sistólica da artéria pulmonar(AP) derivada da curva do refluxo tricúspide, quando presente ${ }^{65}$. Outras técnicas menos precisas incluem a avaliação da pressão diastólica da artéria pulmonar na vigência de refluxo pulmonar, e da pressão média da AP pela análise do fluxo da via de saída do VE.

No tromboembolismo pulmonar agudo ("cor pulmonale" agudo), a ECO-D pode contribuir na avaliação da repercussão hemodinâmica da HP instalada sobre o VD, como manisfestações de episódios embólicos maciços ou submaciços. Pequenas embolias podem não provocar alterações funcionais detectáveis à ECO-D. O exame auxilia também napesquisa da fonte embólica no coração direito e nas veias cavas, bem como possibilita a localização de trombos na AP e seu ramos proximais, principalmente na presença de trombos de maior tamanho. Entretanto, em geral apresenta baixa sensibilidade e especificidade para detectar embolia pulmonar ${ }^{66}$. Nesta situação, o acesso transesofágico pode ser útil.

\section{Arritmias e Síncope}

As arritmias podem resultar de uma alteração funcional eletrofisiológica ou anormalidade estrutural cardíaca. Palpitações são queixas freqüentes, nem sempre relacionadas a arritmias, mas que necessitam de investigação de causa orgânica. A ECO-D é útil na identificação de substrato anatômico para arritmias (disfunções ventriculares, hipertrofia miocárdica, dilatação de câmaras, valvopatias, etc). Na presença de palpitações ou extra-sístoles benignas (ventriculares ou supraventriculares), a ECO-D deve ser indicada se houver suspeita de cardiopatia subjacente. Os pacientes com arritmias ventriculares originadas no ventrículo direito (morfología de BRE) necessitam de ECO-D na busca de evidências de displasia arritmogênica de ventrículo direito. A displasia arritmogênica ventricular direita se caracteriza por peculiar envolvimento do ventrículo direito, instabilidade elétrica que precipita arritmias ventriculares, síncope e

\begin{tabular}{|c|c|}
\hline \multicolumn{2}{|l|}{$\begin{array}{c}\text { Tabela XXIX - Indicações da ecocardiografia em adultos com } \\
\text { arritmias e palpitações }\end{array}$} \\
\hline Indicação & Classe \\
\hline Arritmias ou palpitações com suspeita de cardiopatia estrutural & I \\
\hline $\begin{array}{l}\text { Arritmias em paciente com antecedente familiar de cardiopatia } \\
\text { genética associada a arritmias (ex: miocardiopatía hipertrófica) }\end{array}$ & I \\
\hline Displasia arritmogênica ventricular direita & I \\
\hline $\begin{array}{l}\text { S. Brugada (fibrilação ventricular idiopática) para excluir } \\
\text { doença cardíaca estrutural }\end{array}$ & I \\
\hline Avaliação pré e pós-ablação com suspeita de complicações & I \\
\hline Arritmias que requerem tratamento & IIa \\
\hline Auxílio em técnicas de ablação & IIa \\
\hline $\begin{array}{l}\text { Arritmia ventricular em pacientes candidatos a esportes } \\
\text { competitivos }\end{array}$ & IIa \\
\hline Evidência de pré-excitação no ECG & IIa \\
\hline Pós-ablação sem evidência de complicações & $\mathrm{IIb}$ \\
\hline $\begin{array}{l}\text { ECO transesofágica em fibrilação auricular para } \\
\text { estratificar risco embólico }\end{array}$ & $\mathrm{IIb}$ \\
\hline $\begin{array}{l}\text { Arritmia recorrente que não requer tratamento na presença } \\
\text { de exame físico normal }\end{array}$ & IIb \\
\hline Pré-excitação no ECG na ausência de anomalias cardíacas & $\mathrm{IIb}$ \\
\hline $\begin{array}{l}\text { Palpitações sem arritmia identificada e sem suspeita clínica } \\
\text { de cardiopatía }\end{array}$ & III \\
\hline
\end{tabular}

morte súbita, em que o eco-D pode estabelecer critérios maiores de diagnóstico como severa dilatação, micronaneurismas e hipocinesia do ventrículo direito. As taquicardias ventriculares originadas no ventrículo esquerdo chamam a atenção para disfunção contrátil de ventrículo esquerdo. A ocorrência de fibrilação ventricular na ausência de qualquer alteração estrutural cardíaca é classificada como "doença elétrica primária" ou "fibrilação ventricular idiopática" descrita por Brugada ${ }^{67}$, na qual a ECO-D está indicada para excluir doença cardíaca estrutural.

\subsection{Fibrilação atrial}

A ECO-D transtorácica (ETT) deve ser realizada na avaliação inicial de todos os pacientes com fibrilação atrial (FA), a fim de se determinar o tamanho do átrio esquerdo (AE), o tamanho, espessura miocárdica e função do ventrículo esquerdo (VE), assim como para excluir doenças valvares, pericardiopatias ou miocardiopatia hipertrófica ${ }^{68}$. A análise das funções sistólica e diastólica ajudam na decisão terapêutica. Trombos ocorrem em 10\% dos pacientes com fibrilação atrial, porém cerca de $2 \%$ embolizam, mesmo após restabelecimento da contração mecânica. A sensibilidade do ETT na detecção de trombos no AE varia de 33 a 60\%, mas não é capaz de detectar trombos no apêndice atrial esquerdo (AAE). Já a sensibilidade da ECO transesofágica (ETE ) na detecção de trombos no AE/AAE é de 92\% e a especificidade de $98 \%$. O ETE tem sido usado na FA para se estratificar pacientes em termos do risco de acidente vascular cerebral, para guiar a cardioversão $(\mathrm{CV})$, para identificar pacientes em que a $\mathrm{CV}$ terá sucesso e que irão manter ritmo sinusal ${ }^{69}$. A incidência de 5 a 7\% de eventos embólicos após a $\mathrm{CV}$, em pacientes não anticoagulados, tem sido atri- 


\begin{tabular}{|c|c|}
\hline \multicolumn{2}{|l|}{$\begin{array}{c}\text { Tabela XXX - Indicações de ecocardiograma transesofágico (ETE) } \\
\text { antes da cardioversão (CV) da fibrilação atrial (FA) }\end{array}$} \\
\hline Indicação & Classe \\
\hline $\begin{array}{l}\text { Necessidade de } \mathrm{CV} \text { a curto prazo quando não é possível } \\
\text { aguardar três semanas prévias de anticoagulação oral }\end{array}$ & I \\
\hline $\begin{array}{l}\text { Pacientes com episódios embólicos com provável origem no } \\
\text { apêndice atrial esquerdo }\end{array}$ & I \\
\hline $\begin{array}{l}\text { Pacientes com contraindicação à anticoagulação nos quais a } \\
\text { decisão de CV depende do resultado do ETE }\end{array}$ & I \\
\hline $\begin{array}{l}\text { Pacientes com trombo no apêndice atrial esquerdo demonstrado } \\
\text { em estudo prévio }\end{array}$ & I \\
\hline $\begin{array}{l}\text { Pacientes cuja decisão de CV depende do conhecimento de } \\
\text { fatores prognósticos (função ventricular esquerda, } \\
\text { valvulopatía mitral) (ecocardiografía transtorácica) }\end{array}$ & I \\
\hline $\begin{array}{l}\text { FA }>48 \text { h de duração para decidir CV precoce com heparinização } \\
\text { breve, sem anticoagulação oral prévia de } 3 \text { semanas (ACUTE) }\end{array}$ & I \\
\hline FA aguda $(<48 \mathrm{~h}$ de duração) com cardiopatia prévia & IIa \\
\hline FA aguda ( $<48 \mathrm{~h}$ de duração) sem cardiopatia prévia & $\mathrm{IIb}$ \\
\hline $\begin{array}{l}\text { Pacientes com valvulopatia mitral ou miocardiopatia } \\
\text { hipertrófica com anticoagulação oral crônica adequada }\end{array}$ & $\mathrm{IIb}$ \\
\hline $\begin{array}{l}\text { Pacientes com flutter atrial sem cardiopatia estrutural que } \\
\text { necessitam CV }\end{array}$ & $\mathrm{IIb}$ \\
\hline CV elétrica de urgência (FA com instabilidade hemodinâmica, etc) & III \\
\hline $\begin{array}{l}\text { Pacientes com anticoagulação crônica prévia, INR terapêutico } \\
(2,0-3,0) \text {, sem valvulopatia mitral ou miocardiopatia } \\
\text { (dilatada, hipertrófica) }\end{array}$ & III \\
\hline $\begin{array}{l}\text { Pacientes com ETE prévio recente comprovando ausência de } \\
\text { trombo atrial esquerdo, sem novas alterações clínicas }\end{array}$ & III \\
\hline
\end{tabular}

buída ao deslocamento de trombo previamente existente. Contudo, estudos recentes demonstraram uma disfunção do AE e do AAE após reversão a ritmo sinusal, potencialmente tromboembolígena, o que explica os eventos embólicos em pacientes sem trombos ao ETE prévio à $\mathrm{CV}^{70}$. A exclusão de trombos intra-atriais pelo ETE possibilita redução do tempo de anticoagulação pré-CV ${ }^{71}$. O estudo multicêntrico ACUTE propôs uma alternativa segura e eficaz de anticoagulação breve com heparinização terapêutica endovenosa para pacientes com FA não valvular de duração superior a 48 horas, seguida de ETE para excluir trombo em AE/ AAE, acompanhada de 4 semanas de anticoagulação oral após $\mathrm{CV}$ bem sucedida ${ }^{72}$. Esta opção parece ser adequada para pacientes com FA de início recente $(<3$ semanas) que necessitam CV precoce. Na FA aguda $(<48 \mathrm{~h})$ há evidências recentes de formação de trombo no AAE em $14 \%$ dos pacientes nessa condição ${ }^{73}$, levantando a possibilidade de anticoagulação em pacientes de alto risco. Embora a presença de trombos no flutter pareça ser menor que na FA ou na FA/flutter ${ }^{74}$, não existem estudos sobre o papel da anticoagulação pré-CV e ETE nessa arritmia. Nesta situação, a presença de fatores de risco embólico (estenose mitral, miocardiopatia, ICC, embolia prévia) deve ser levada em consideração para a melhor estratégia terapêutica.

\subsection{Síncope}

As causas mais comuns de síncope são reflexos vasodepressores, bradi ou taquiarritmias. Sintomas como tonturas não rotatórias, acompanhadas de palidez, sudorese, es-

\begin{tabular}{|lc|}
\hline \multicolumn{2}{|c|}{ Tabela XXXI - Indicações da ecocardiografia na síncope } \\
\hline Indicação & Classe \\
\hline Síncope em paciente com suspeita de cardiopatia estrutural & I \\
Síncope relacionada ao exercício & I \\
$\begin{array}{l}\text { Síncope em atividade ocupacional de alto risco } \\
\text { (ex: pilotos, motoristas, bombeiros, etc) }\end{array}$ & IIa \\
$\begin{array}{l}\text { Síncope de etiologia obscura sem evidência clínica } \\
\text { de cardiopatia }\end{array}$ & IIb \\
Síncope recorrente de causa já estabelecida & III \\
Síncope neurogênica clássica ou de outra causa & III \\
sabidamente não cardíaca & \\
\hline
\end{tabular}

curecimento de visão, relacionados ou não aos esforços, devem ser investigadas, pois podem preceder síncope (présíncope). O papel do ECO-D na síncope se baseia na identificação de lesões estruturais, potencialmente arritmogênicas, como disfunção ventricular e/ou hipertrofia miocárdica, além de condições que possam causar hipofluxo cerebral, como obstrução à via de saída de entrada ou saída dos ventrículos por hipertrofia, trombos ou tumores, tromboembolismo ou hipertensão pulmonar e dissecção aórtica.A justificativa do uso de ecocardiograma no estudo de síncope de origem desconhecida, como rotina, é controvertida, uma vez que os estudos são retrospectivos.

\section{Massas Intracardíacas e Tumores Cardíacos}

Massas cardíacas identificáveis pela ecocardiografia transtorácica, e se necessário pela técnica transesofágica, incluem tumores cardíacos primários ou secundários. As massas intracardíacas sésseis ou pedunculadas, devem ser diferenciadas entre tumores, trombos, vegetações endocárdicas bacterianas, ou vegetações trombóticas não bacterianas das colagenoses e doenças consumptivas (marânticas), pelo contexto clínico do paciente. A massa pode ser um achado ocasional em exame de rotina, ou ser suspeitada em vigência de processos embólicos múltiplos, neurológi-

\begin{tabular}{|c|c|}
\hline \multicolumn{2}{|c|}{$\begin{array}{c}\text { Tabela XXXII - Indicações da ecocardiografia em pacientes com } \\
\text { massas intracardíacas e tumores }\end{array}$} \\
\hline Indicação & Classe \\
\hline $\begin{array}{l}\text { Avaliação de quadros clínicos que sugiram a } \\
\text { possibilidade de massa intracardíaca de natureza não } \\
\text { esclarecida, cuja decisão terapêutica envolvendo cirurgia } \\
\text { ou anticoagulação depende do resultado do exame * }\end{array}$ & I \\
\hline $\begin{array}{l}\text { Acompanhamento evolutivo após remoção cirúrgica de } \\
\text { massas com possibilidade de recorrência* }\end{array}$ & I \\
\hline $\begin{array}{l}\text { Pacientes com neoplasia maligna e possibilidade de } \\
\text { envolvimento cardíaco* }\end{array}$ & I \\
\hline $\begin{array}{l}\text { Rastreamento de pacientes com condições } \\
\text { predisponentes à formação de massas intracardíacas, } \\
\text { mas sem evidências clínicas }\end{array}$ & IIa \\
\hline $\begin{array}{l}\text { Pacientes cujo resultado da ECO-D não terá impacto } \\
\text { na decisão terapêutica }\end{array}$ & III \\
\hline
\end{tabular}


cos ou periféricos, febre prolongada, variações auscultatórias de sopros cardíacos, ou possibilidade de malignidade com acometimento de câmaras cardíacas ou do espaço pericárdico. Os tumores mais comuns no adulto são de natureza benigna, representados pelo mixoma, e menos freqüente pelo fibroelastoma, ambos com potencial embolígeno, quando pedunculados e móveis. Mais raros são os tumores malignos como sarcomas e linfomas infiltrando as paredes cardíacas, ou invadindo as cavidades como os hipernefromas, melanomas e tumores torácicos primários. Massas intramiocárdicas podem sugerir fibromas, ou rabdomiomas quando múltiplas e presentes em crianças. Derrames pericárdicos recorrentes de causa indeterminada devem levantar a suspeita de metástase pericárdica ${ }^{1-3}$.

\section{Doenças do Pericárdio}

A ECO-D transtorácica é o método mais usado para avaliação semiquantitativa do derrame pericárdico e suas conseqüências hemodinâmicas, que dependem não só do volume de líquido coletado, mas sobretudo da velocidade de sua instalação. São necessários múltiplos planos para a caracterização de derrame septado, comum no pós-operatório de cirurgia cardíaca sob a forma de hematoma pericárdico. Conteúdos sólidos podem ser reconhecidos no interior do espaço pericárdico, associados a líquido (gordura epicárdica, grumos de exsudato, fibrina, coágulos ou massas tumorais, geralmente metastáticas), porém não podem ser diferenciados de forma precisa. Sinais de restrição externa podem ser determinados e necessitam de exames evolutivos para detectar precocemente o tamponamento cardíaco, que é um processo dinâmico. Inicia-se com colapso das câmaras direitas, evolui para acentuação das variações respiratórias dos fluxos transvalvares, e sinais de pletora da veia cava inferior, que podem anteceder as manifestações clínicas de tamponamento. Pericardites "secas", fibrinosas por vezes não se acompanham de derrame pericárdico.

\begin{tabular}{|c|c|}
\hline $\begin{array}{c}\text { Tabela XXXIII - Indicações da ecocardiografia nas doenças } \\
\text { pericárdio classe }\end{array}$ & \\
\hline Avaliação & Classe \\
\hline $\begin{array}{l}\text { Suspeita de derrame pericárdico por doença pericárdica } \\
\text { primária (pericardite quilotórax exsudativa) ou secundária } \\
\text { (sangramento, metástase, mixedema, hidropericárdio, } \\
\text { quilotórax, etc) }\end{array}$ & I \\
\hline $\begin{array}{l}\text { Suspeita de processo restritivo externo por doença } \\
\text { pericárdica primária (pericardite constritiva) ou } \\
\text { secundária (compressão tumoral) }\end{array}$ & I \\
\hline $\begin{array}{l}\text { Estudos evolutivos para avaliação de derrames recorrentes } \\
\text { ou para detecção precoce de processo constritivo }\end{array}$ & I \\
\hline $\begin{array}{l}\text { Suspeita de tamponamento por hemorragia secundária a } \\
\text { trauma torácico, perfuração iatrogênica durante cateterismo, } \\
\text { rotura de parede ventricular durante infarto agudo do } \\
\text { miocárdio e dissecção aórtica }\end{array}$ & I \\
\hline Monitoramento de punção pericárdica guiada por ecocardiograma & Iia \\
\hline Exame de rotina para pequenos derrames em pacientes estáveis & III \\
\hline $\begin{array}{l}\text { Pesquisa de espessamento pericárdico sem repercussão } \\
\text { hemodinâmica }\end{array}$ & III \\
\hline
\end{tabular}

O espessamento pericárdico é um achado inespecífico, dependente de fatores técnicos. A pericardite constritiva pode ocorrer sem calcificações pericárdicas evidentes, mas pode ser suspeitada pelas alterações hemodinâmicas, que resultam nas variações fásicas respiratórias de fluxos das valvas cardíacas e veias hepáticas, além da pletora da veia cava inferor. Em exames inconclusivos para derrame, espessamento ou constrição pericárdica, um ECO transesofágico deverá ser realizado.

Cistos pericárdicos, tumores císticos e agenesia de pericárdio constituem outras situações menos freqüentes que podem ser diagnosticadas à ECO-D ${ }^{1-3}$.

\section{Doenças da Aorta Torácica, Artéria Pulmonar, Veias Cavas e Pulmonares}

A porção proximal da aorta ascendente, do arco aórtico e do tronco da artéria pulmonar podem ser avaliados pela ECO transtorácica (ETT). As janelas supraesternal e subcostal são utilizadas para complementação do estudo das veias cavas, pulmonares e da aorta abdominal proximal. Uma adequada visibilização das porções tranversa e descendente da aorta torácica, do segmento proximal dos ramos da artéria pulmonar, da desembocadura das veias pulmonares e da das veias cavas necessita do exame transesofágico (ETE). Nas síndromes aórticas agudas (dissecção aórtica, hematoma intramural e úlcera aterosclerótica penetrante), bem como nos aneurismas aórticos verdadeiros (não complicados, ou com suspeita de rotura), o envolvimento proximal da aorta pode ser suspeitado ao ETT, necessitando do ETE para melhor acurácia diagnóstica da doença, da extensão do envolvimento, da caracterização dos orifícios de entrada e das luzes verdadeira e falsa, e de eventuais complicações (derrame pericárdico, insuficiência aórtica). Trauma torácico fechado com suspeita de transecção aórtica exige o ETE na ausência de complicações esofagianas. O ETE

\begin{tabular}{|c|c|c|}
\hline \multicolumn{3}{|l|}{$\begin{array}{c}\text { Tabela XXXIV - Indicações de ecocardiografia nas } \\
\text { doenças da aorta classe }\end{array}$} \\
\hline Indicação & $\begin{array}{l}\text { Cla } \\
\text { ETT }\end{array}$ & $\begin{array}{l}\text { sse } \\
\text { ETE }\end{array}$ \\
\hline $\begin{array}{l}\text { Dissecção aórtica e suas variantes (hematoma } \\
\text { intramural, úlcera aterosclerótica penetrante) }\end{array}$ & IIa & I \\
\hline $\begin{array}{l}\text { Aneurismas aórticos verdadeiros (ateroscleróticos, } \\
\text { Marfan e doenças do tecido conjuntivo) }\end{array}$ & I & I \\
\hline Rotura traumática da aorta (dissecção ou transeccção) & IIa & I \\
\hline $\begin{array}{l}\text { Doenças degenerativas (aterotrombose) ou inflamatórias } \\
\text { (arterites) da aorta torácica, com fenômenos } \\
\text { tromboembólicos ou oclusões arteriais crônicas }\end{array}$ & IIa & I \\
\hline $\begin{array}{l}\text { Acompanhamento evolutivo de dissecções ou suas } \\
\text { variantes, após tratamento conservador, procedimentos } \\
\text { intervencionistas ("stent"), ou cirurgia, sem complicações }\end{array}$ & I & IIa \\
\hline $\begin{array}{l}\text { Acompanhamento evolutivo de dissecções ou suas variantes, } \\
\text { após tratamento conservador, procedimentos intervencionistas } \\
\text { ("stent"), ou cirurgia, com suspeita de progressão ou complicaçã }\end{array}$ & I & I \\
\hline $\begin{array}{l}\text { Rastreamento familiar de parentes de pacientes com síndrome } \\
\text { de Marfan ou outras doenças do tecido conjuntivo }\end{array}$ & I & I \\
\hline Suspeita de arterite de Takayasu & I & I \\
\hline
\end{tabular}


também é necessário na avaliação da aorta como fonte embolígena na suspeita de aterotrombose da aorta torácica com a formação de placas ateroscleróticas móveis, associadas a trombos, ou placas ulceradas complexas, com espessura superior a $4 \mathrm{~mm}$. Nas doenças inflamatórias crônicas, como na arterite de Takayasu, o ETT pode detectar complicações (dilatação da aorta ascendente, insuficiência aórtica), e o ETE pode caracterizar o espessamento parietal e a perda de elasticidade das paredes aórticas ${ }^{1-3}$.

\section{Cardiologia Pediatria, Cardiologia Fetal e Cardiopatias Congênitas no Adulto}

A ecocardiografia tornou-se o método diagnóstico definitivo para o reconhecimento e acompanhamento das cardiopatias congênitas e adquiridas no grupo pediátrico, o que diminui a necessidade de exames invasivos, facilitando a conduta médica ou cirúrgica. Serão descritas as indicações habituais do exame nas formas congênitas e adquiridas das doenças cardíacas no feto, no recém-nascido, na infância e adolescência, além das doenças congênitas em adultos.

\subsection{Ecocardiografia fetal}

Considerando a importância prognóstica do diagnóstico intra-uterino rede cardiopatias congênitas e arritmias graves, todos os esforços devem ser mobilizados no senti-

\begin{tabular}{|c|c|}
\hline \multicolumn{2}{|l|}{ Tabela XXXV - Indicações da ecocardiografia fetal } \\
\hline Indicação & Classe \\
\hline $\begin{array}{l}\text { Detecção ou exclusão de anormalidades cardíacas fetais } \\
\text { como rotina da avaliação pré-natal, independentemente da } \\
\text { presença de fatores de risco para cardiopatias }\end{array}$ & I \\
\hline Translucência nucal aumentada no primeiro trimestre & I \\
\hline $\begin{array}{l}\text { Detecção ou suspeita de alterações cardíacas à } \\
\text { ultra-sonografia obstétrica }\end{array}$ & I \\
\hline Presença de alterações do rítmo cardíaco & I \\
\hline Presença de fatores de risco materno-familiar para cardiopatias & I \\
\hline Cariótipo alterado & I \\
\hline Diabetes materno & I \\
\hline Lupus eritematoso sistêmico ou outra colagenose materna & I \\
\hline Exposição a agentes teratogênicos & I \\
\hline $\begin{array}{l}\text { Uso materno de indometacina, aspirina, anti-inflamatórios } \\
\text { e outros medicamentos que interfiram no metabolismo } \\
\text { da prostaglandina }\end{array}$ & $\mathrm{I}$ \\
\hline $\begin{array}{l}\text { Anormalidades extracardíacas detectadas à } \\
\text { ultra-sonografia obstétrica }\end{array}$ & I \\
\hline História de perdas fetais anteriores & I \\
\hline Retardo do crescimento intra-uterino & I \\
\hline Oligodrâmnio ou polidrâmnio & I \\
\hline Hidropsia fetal não imunológica & I \\
\hline Idade materna avançada & I \\
\hline $\begin{array}{l}\text { Uso materno de substâncias com potencial efeito deletério } \\
\text { sobre o coração fetal (álcool, fumo e drogas com ação sobre } \\
\text { o sistema nervoso central) }\end{array}$ & I \\
\hline Infecções virais ou parasitárias maternas & $\mathrm{I}$ \\
\hline $\begin{array}{l}\text { Avaliação do coração fetal no primeiro trimestre } \\
\text { da gestação por ecocardiografia transvaginal }\end{array}$ & $\mathrm{IIb}$ \\
\hline
\end{tabular}

do de se avaliar o coração fetal em todas as gestações através da ecocardiografia fetal ${ }^{75-77}$. A ecocardiografia fetal passou a ser ferramenta fundamental para o diagnóstico cardiológico intra-uterino. A implicação imediata desse fato é a de que muitas cardiopatias graves, com necessidade de atendimento clínico-cirúrgico de emergência logo após o nascimento, passaram a ter seu diagnóstico conhecido ainda na vida intra-uterina, propiciando o planejamento antecipado das ações a serem adotadas pela equipe médica no pós-parto imediato ${ }^{78-80}$. O exame pode ser realizado no primeiro trimestre, tanto por via transvaginal como transabdominal. Entretanto, é a partir da $18^{\mathrm{a}}$ semana de gestação, até o termo, que todas as alterações estruturais ou funcionais do coração fetal podem ser identificadas ${ }^{81}$. Sugere-se utilizar a análise segmentar para identificação e descrição das estruturas cardíacas, e estudo pelas técnicas de Doppler pulsátil e mapeamento de fluxo em cores para a avaliação dos fluxos nas grandes artérias, valvas e cavidades cardíacas, assim como canal arterial, ducto venoso, veias pulmonares, sistema venoso abdominal, artéria e veia umbilicais e artéria cerebralmédia.

\subsection{Ecocardiografia em recém-nascidos}

Nas indicações da ecocardiografia para o grupo de pacientes recém-nascidos deve-se levar em conta a fisiologia cardiovascular de transição do feto para a fase pós-natal, assim como a freqüente coexistência de doenças pulmonares ${ }^{82-84}$.

\subsection{Ecocardiograma em lactentes, crianças e adolescentes}

Em lactentes, crianças e adolescentes, as principais indicações da Doppler-ecocardiografia incluem alterações da

\begin{tabular}{|c|c|}
\hline \multicolumn{2}{|c|}{ Tabela XXXVI - Indicações para ecocardiografia no recém-nascido } \\
\hline Indicação & Classe \\
\hline Cianose, desconforto respiratório, insuficiência cardíaca & I \\
\hline $\begin{array}{l}\text { Anormalidades cromossômicas ou anomalias extracardíacas } \\
\text { com probabilidade de coexistir com cardiopatia }\end{array}$ & I \\
\hline $\begin{array}{l}\text { Ausência de melhora esperada da função cardiopulmonar em } \\
\text { prematuro com doença pulmonar }\end{array}$ & I \\
\hline Doença sistêmica materna associada a morbidade neonatal & I \\
\hline Sopro intenso ou outra anormalidade cardíaca & I \\
\hline $\begin{array}{l}\text { Síndrome com herança dominante associada a cardiopatia } \\
\text { ou incidência em vários membros da família }\end{array}$ & I \\
\hline Cardiomegalia ao RX-tórax & I \\
\hline $\begin{array}{l}\text { Dextrocardia, anomalias de situs visceral ou pulmonar } \\
\text { ao exame clínico, ECG ou radiografia. }\end{array}$ & I \\
\hline Arritmias e/ou distúrbios da condução elétrica & I \\
\hline Hidropisia fetal não imunológica & I \\
\hline $\begin{array}{l}\text { Acompanhamento de neonato submetido a fechamento } \\
\text { de canal arterial. }\end{array}$ & I \\
\hline Sopro suave na borda esternal inferior esquerda & IIa \\
\hline $\begin{array}{l}\text { Dificuldade de crescimento na ausência de anormalidade } \\
\text { clínica definida }\end{array}$ & IIa \\
\hline $\begin{array}{l}\text { Síndrome associada a cardiopatia congênita sem evidência } \\
\text { clínica de anormalidade cardíaca }\end{array}$ & $\mathrm{IIb}$ \\
\hline $\begin{array}{l}\text { Ritmo cardíaco ectópico fetal não sustentado e ausência } \\
\text { de arritmia pós-parto }\end{array}$ & III \\
\hline
\end{tabular}




\begin{tabular}{|c|c|}
\hline \multicolumn{2}{|l|}{$\begin{array}{c}\text { Tabela XXXVII - Indicações para ecocardiografia em lactentes, } \\
\text { crianças e adolescentes }\end{array}$} \\
\hline Indicação & Classe \\
\hline $\begin{array}{l}\text { Sopro atípico ou patológico ou outra evidência de } \\
\text { anormalidade cardíaca }\end{array}$ & I \\
\hline Cardiomegalia à radiografia & I \\
\hline $\begin{array}{l}\text { Dextrocardia, anomalias de situs visceral ou pulmonar } \\
\text { ao exame clínico, ECG ou radiografial }\end{array}$ & I \\
\hline $\begin{array}{l}\text { Determinação do momento adequado para tratamento } \\
\text { clínico ou cirúrgico de paciente com defeito cardíaco conhecido. }\end{array}$ & I \\
\hline $\begin{array}{l}\text { Avaliação pré-operatória imediata para orientação de } \\
\text { manuseio cirúrgico em paciente com defeito cardíaco conhecido }\end{array}$ & I \\
\hline $\begin{array}{l}\text { Mudança evolutiva no quadro clínico de paciente com } \\
\text { defeito cardíaco conhecido }\end{array}$ & I \\
\hline Arritmias e/ou distúrbios da condução elétrica do coração & I \\
\hline $\begin{array}{l}\text { Avaliação pós-operatória com suspeita clínica de lesão } \\
\text { residual ou anormalidade recorrente, função contrátil } \\
\text { diminuída, hipertensão arterial pulmonar, trombo, } \\
\text { septicemia, ou derrame pericárdico }\end{array}$ & I \\
\hline $\begin{array}{l}\text { Síndrome com herança dominante associada à } \\
\text { cardiopatia ou com incidência em vários membros da família }\end{array}$ & I \\
\hline História familiar de doença miocárdica transmitida geneticamente & I \\
\hline Fenótipos de síndrome de Marfan ou Elhers-Danlos & I \\
\hline Doença neuromuscular associada ao envolvimento miocárdico & I \\
\hline $\begin{array}{l}\text { Síndrome associada à alta incidência de cardiopatia } \\
\text { congênita sem evidência clínica de anomalia cardíaca }\end{array}$ & I \\
\hline Síncope ou dor precordial induzida por esforço físico & I \\
\hline $\begin{array}{l}\text { Febre prolongada sem causa aparente em paciente com } \\
\text { cardiopatia congênita }\end{array}$ & I \\
\hline Sopro funcional em paciente assintomático & IIa \\
\hline $\begin{array}{l}\text { Retardo de crescimento na ausência de anormalidade } \\
\text { clínica definida. }\end{array}$ & $\mathrm{IIb}$ \\
\hline Avaliação pós-operatória recente sem suspeita de lesão residual & $\mathrm{IIb}$ \\
\hline $\begin{array}{l}\text { Avaliação pós-operatória tardia de paciente assintomático, } \\
\text { sem anormalidade clínica ou recorrente }\end{array}$ & III \\
\hline $\begin{array}{l}\text { Dor torácica de origem músculo-esquelética em } \\
\text { paciente assintomático }\end{array}$ & III \\
\hline
\end{tabular}

anatomia, da função, da morfogênese e do rítmo cardíaco. O principal papel do exame está na completa caracterização da lesão de pacientes com suspeita clínica, na avaliação da história natural, no reconhecimento e na prevenção de mudanças secundárias, assim como na resposta ao tratamento dispensado ${ }^{85-96}$.

\subsection{Crianças com cardiopatias adquiridas}

A Doppler-ecocardiografia permite informações importantes na avaliação das principais categorias de cardiopatias adquiridas no grupo pediátrico. Tais cardiopatias ocorrem principalmente em doenças sistêmicas associadas a processos inflamatórios, drogas cardiotóxicas, transplante cardíaco, doença parenquimatosa pulmonar e trombos ${ }^{97-101}$.

\subsection{Adultos com cardiopatias congênitas}

Pacientes adultos podem apresentar cardiopatias congênitas diagnosticadas na infância, não operadas ou que foram previamente submetidas a cirurgia paliativa ou corretiva. Alguns podem manifestar tardiamente cardiopatias congênitas não diagnosticadas na infância ${ }^{102}$.

\begin{tabular}{|c|c|}
\hline Indicação & Classe \\
\hline $\begin{array}{l}\text { Avaliação inicial e reavaliações de pacientes com } \\
\text { diagnóstico suspeito ou confirmado de } \\
\text { síndrome de Kawasaki, miopericardites, HIV e febre reumática. }\end{array}$ & I \\
\hline $\begin{array}{l}\text { Pós-transplante cardíaco, para monitorização de } \\
\text { sinais de rejeição, trombo e crescimento cardíaco }\end{array}$ & I \\
\hline $\begin{array}{l}\text { Avaliação inicial e reavaliação de pacientes em uso } \\
\text { de droga cardiotóxica }\end{array}$ & I \\
\hline Evidência clínica de doença miocárdica & I \\
\hline Insuficiência renal grave e evidência de anormalidade cardíaca & I \\
\hline Avaliação de doadores para transplante cardíaco & I \\
\hline Hipertensão arterial pulmonar & I \\
\hline Evento trombo-embólico & I \\
\hline $\begin{array}{l}\text { Septicemia, insuficiência cardíaca direita e cianose } \\
\text { em paciente com cateter venoso }\end{array}$ & I \\
\hline $\begin{array}{l}\text { Embolização sistêmica ou pulmonar em paciente } \\
\text { com shunt cardíaco e com cateter venoso }\end{array}$ & I \\
\hline Síndrome da veia cava superior em paciente com cateter venoso & I \\
\hline Diagnóstico de provável febre reumática em atividade & I \\
\hline Septicemia & IIa \\
\hline Fibrose cística sem evidência de cor pulmonale & IIa \\
\hline $\begin{array}{l}\text { Acompanhamento de pacientes após febre reumática } \\
\text { sem evidência de envolvimento cardíaco }\end{array}$ & $\mathrm{IIb}$ \\
\hline $\begin{array}{l}\text { Avaliação tardia após pericardite, sem evidências de } \\
\text { pericardite recorrente ou pericardite crônica }\end{array}$ & $\mathrm{IIb}$ \\
\hline $\begin{array}{l}\text { Acompanhamento tardio de síndrome de Kawasaki sem } \\
\text { evidência de anormalidade coronariana na fase aguda }\end{array}$ & III \\
\hline $\begin{array}{l}\text { Avaliação de rotina em paciente assintomático com } \\
\text { cateter venoso }\end{array}$ & III \\
\hline
\end{tabular}

\begin{tabular}{|c|c|}
\hline \multicolumn{2}{|l|}{$\begin{array}{c}\text { Tabela XXXIX - Indicações para ecocardiografia em adultos com } \\
\text { cardiopatias congênitas }\end{array}$} \\
\hline Indicação & Classe \\
\hline $\begin{array}{l}\text { Suspeita clínica evidenciada por sopro, cianose, } \\
\text { insaturação arterial, anormalidade ao ECG ou radiografia }\end{array}$ & I \\
\hline $\begin{array}{l}\text { Mudança no quadro clínico em paciente com cardiopatia } \\
\text { congênita conhecida }\end{array}$ & I \\
\hline $\begin{array}{l}\text { Dúvidas do diagnóstico original ou anormalidades } \\
\text { estruturais ou hemodinâmicas não esclarecidas em } \\
\text { paciente com cardiopatia congênita conhecida }\end{array}$ & I \\
\hline $\begin{array}{l}\text { Acompanhamento periódico de pacientes com } \\
\text { cardiopatia congênita nos quais a avaliação da função } \\
\text { contrátil e do refluxo valvar atrioventricular é necessária. }\end{array}$ & I \\
\hline $\begin{array}{l}\text { Acompanhamento da pressão arterial pulmonar } \\
\text { em pacientes com cardiopatias com fator de risco } \\
\text { adicional para hipertensão pulmonar }\end{array}$ & I \\
\hline $\begin{array}{l}\text { Orientação de cateterismo intervencionista terapêutico } \\
\text { (valvotomia, ablação por radiofreqüência, fechamento } \\
\text { percutâneo da comunicação interatrial de canal arterial) }\end{array}$ & I \\
\hline $\begin{array}{l}\text { Acompanhamento anual ou bienal de pacientes com } \\
\text { cardiopatia congênita com repercussão hemodinâmica } \\
\text { conhecida, sem evidência de mudança na condição clínica }\end{array}$ & IIb \\
\hline $\begin{array}{l}\text { Acompanhamento de pacientes com comunicação } \\
\text { interventricular (potencial para modificações } \\
\text { morfológicas evolutivas) }\end{array}$ & I \\
\hline $\begin{array}{l}\text { Exames periódicos em pacientes operados de PCA, CIA, } \\
\text { CIV, coarctação da aorta ou valva aórtica bivalvular, } \\
\text { sem mudanças na condição clínica. }\end{array}$ & III \\
\hline $\begin{array}{l}\text { Acompanhamento de pacientes com cardiopatias } \\
\text { sem significado hemodinâmico, sem mudança na condição clínica }\end{array}$ & III \\
\hline
\end{tabular}




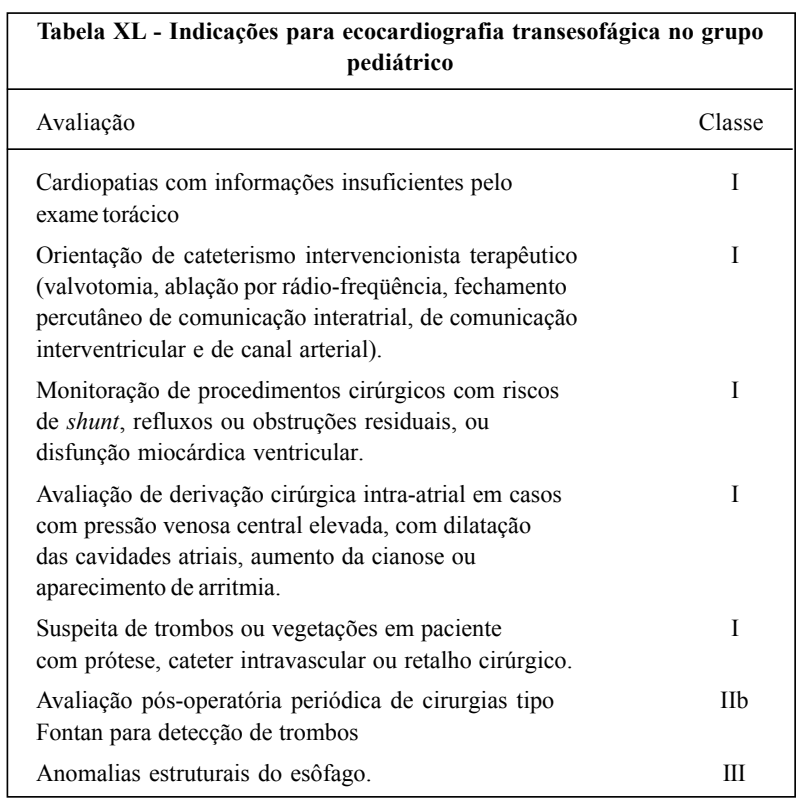

\begin{tabular}{|c|c|}
\hline \multicolumn{2}{|c|}{$\begin{array}{c}\text { Tabela XLI - Indicações para ecocardiografia sob estresse } \\
\text { no grupo pediátrico }\end{array}$} \\
\hline Indicação & Classe \\
\hline $\begin{array}{l}\text { Pesquisa de insuficiência coronária em crianças } \\
\text { pós-transplante cardíaco tardio }\end{array}$ & I \\
\hline $\begin{array}{l}\text { Pesquisa de insuficiência coronária em crianças com } \\
\text { doença de Kawasaki, pós-operatório de cirurgia de Jatene, } \\
\text { pós peratório de origem e trajetos anormais das artérias } \\
\text { coronárias e fístulas coronário-cavitárias }\end{array}$ & IIa \\
\hline $\begin{array}{l}\text { Função ventricular nas miocardiopatias e nas insuficiências } \\
\text { valvares mitral e aórtica }\end{array}$ & IIa \\
\hline $\begin{array}{l}\text { Pesquisa de insuficiência coronária em crianças com } \\
\text { atresia pulmonar com septo ventricular íntegro, } \\
\text { dislipidemia, diabetes mellitus insulino-dependente, } \\
\text { estenose aórtica supravalvar }\end{array}$ & $\mathrm{IIb}$ \\
\hline $\begin{array}{l}\text { Avaliação do comportamento do gradiente de pressão } \\
\text { em cardiomiopatia hipertrófica, estenoses valvares } \\
\text { pulmonar e aórtica }\end{array}$ & $\mathrm{IIb}$ \\
\hline
\end{tabular}

\begin{tabular}{|c|c|}
\hline \multicolumn{2}{|c|}{$\begin{array}{c}\text { Tabela XLII - Indicações de ecocardiografia em indivíduos adultos } \\
\text { sem sintomas cardíacos }\end{array}$} \\
\hline Indicação & Classe \\
\hline $\begin{array}{l}\text { Paciente com história familiar de doença cardiovascular } \\
\text { genéticamente transmitida }\end{array}$ & I \\
\hline $\begin{array}{l}\text { Parentes de } 1^{\circ} \text {. grau de pacientes com cardiomiopatia } \\
\text { dilatada idiopática }\end{array}$ & I \\
\hline Potencial doador para transplante cardíaco & I \\
\hline $\begin{array}{l}\text { Paciente com fenótipo de síndrome de Marfan ou doença } \\
\text { relacionada a tecido conectivo }\end{array}$ & I \\
\hline $\begin{array}{l}\text { Avaliação inicial e acompanhamento de } \\
\text { pacientes em tratamento quimioterápico cardiotóxico }\end{array}$ & I \\
\hline $\begin{array}{l}\text { Pacientes com doença sistêmica com potencial } \\
\text { comprometimento cardíaco }\end{array}$ & $\mathrm{IIb}$ \\
\hline População em geral com avaliação de rotina em assintomáticos & III \\
\hline
\end{tabular}

\subsection{Ecocardiografiatransesofágicaemcardiologiapediátrica}

A ecocardiografia transesofágica adiciona importantes informações para a avaliação cardiológica, oferecendo excelente resolução de estruturas cardíacas e paracardíacas na maioria dos pacientes no grupo pediátrico, principalmente nos casos em que a definição das imagens pelo exame transtorácico é inadequado. Além disso, a técnica pode ser utilizada em associação com o cateterismo na orientação de procedimentos terapêuticos ou durante o período intraoperatório para a avaliação imediata dos resultados cirúrgicos ${ }^{102}$.

\subsection{Ecocardiografia sob estresse em cardiologia pediátrica}

Largamente utilizada em adultos, a ecocardiografia sob estresse pode também ser útil em crianças com cardiopatias congênitas ou adquiridas na infância. O estresse pode ser com esforço físico ou farmacológico ${ }^{103}$.

\section{Uso do Ecocardiograma em Situações Específicas}

\subsection{Na sala de emergência e no paciente criticamente en- fermo sob cuidados intensivos}

Nos pacientes graves na sala de emergência, assim como nos pacientes críticos de UTI, de unidade pós-operatória, o ECO em geral determina grande impacto nas tomadas imediatas de decisão e nos resultados terapêuticos. Nesta categoria incluem-se aqueles com dor torácica, instabilidade hemodinâmica, hipotensão ou choque circulatório de causa não esclarecida, dispnéia súbita ou franca insuficiência respiratória aguda, que necessitam de uma ágil ferramenta de avaliação da função ventricular e/ou valvar, do estado volêmico e de eventuais processos de tamponamento pericárdico, tromboembolismo pulmonar ou dissecção aórtica. Outro grupo importante de pacientes críticos que se beneficiam do diagnóstico imediato da $\mathrm{ECO}$, diz respeito à pesquisa de fonte embolígena ou de febre de origem indeterminada (afastar endocardite infecciosa nos pacientes com múltiplas vias de entrada: cateteres, sondas, curativos, etc). Algumas particularidades nesses doentes acrescentam dificuldades técnicas ao exame: ventilação mecânica, curativos torácicos ou abdominais, decúbito dorsal obrigatório, inconsciência com impossibilidade de cooperação, além de sondas, cateteres, eletrodos, que prejudicam a análise pelas janelas transtorácica ou subcostal habituais. Nesta situação, o uso da ECO transesofágica traz vantagens relevantes, pela sua rapidez, acurácia e versatilidade, sobre outras modalidades de diagnóstico de imagem, sobretudo pelo fato de ser facilmente transportável até o ambiente de UTI, na impossibilidade de locomoção do paciente grave e instável. O uso de aparelhos portáteis (hand-carried ultrasound) tem sido proposto para avaliação rápida e focalizada em certas urgências médicas, porém seu real valor sobre a aparelhagem convencional ainda não está estabelecido.

\subsection{No Paciente politraumatizado}

Tais pacientes constituem outra parcela que se beneficia do rápido diagnóstico de tamponamento cardíaco, con- 
tusão cardíaca e traumas da aorta torácica (dissecção, transecção), que constituem emergências médicas. Pelos mesmos motivos anteriores, estes doentes apresentam limitações técnicas para realização do ECO transtorácico, acrescida da possibilidade de enfisema subcutâneo, que impede a visibilização do coração por esta via. O uso da ECO transesofágica pode contornar o problema, exceto na suspeita de perfuração de esôfago nos traumas fechados ou por objetos penetrantes.

\subsection{Avaliação cardiológica de rotina em assintomáticos (check-up) ou rastreamento populacional de cardiopatia (screnning)}

Embora seja um método sem risco, o custo financeiro do ECO impede seu uso indiscriminado, não sendo indicado para levantamentos sistemáticos de possíveis cardiopatias em populações assintomáticas. Abaixo, estão indicadas as situações do uso deste método.

\subsection{Avaliação cardiológica na gestação}

A gestação normal se caracteriza por adaptações cardiocirculatórias fisiológicas frente à demanda metabólica aumentada, com manifestações clínicas que podem sugerir envolvimento cardíaco (dispnéia,sopros, palpitações, edema periférico). A ECA-D pode ser realizada na suspeita de cardiopatia e gravidez, sem prejuízo ao feto. Mínimos aumentos das cavidades cardíacas, sobretudo das direitas, sem ultrapassar os parâmetros normais, podem ocorrer na gravidez normal como resultado do aumento da volemia, sem comprometimento da função ventricular. Podem ser observados refluxos multivalvares fisiológicos, à exceção do refluxo aórtico ${ }^{104}$. A presença de aumento anormal do ventrículo esquerdo em gestantes assintomáticas deve exigir esclarecimento e acompanhamento, devido à possibilidade de desenvolvimento de miocardiopatia específica periparto. Gestantes com valvopatia estável devem realizar eco trimestral ${ }^{105}$, ou quando houver mudanças de sintomas. Em valvopatias na gestação deve ser lembrada a possibilidade do aumento transitório de gradientes valvares, resultante do aumento do débito cardíaco. Dilatação da raiz aórtica e da aorta ascendente merecem atenção especial, sobretudo em parentes de $1^{\circ}$. grau de portadores de síndrome de Marfan.

\subsection{No coração do atleta}

Certas atividades físicas contínuas determinam adaptações fisiológicas em função da natureza do trabalho desenvolvido, que devem ser diferenciadas de cardiopatia estrutural. Embora a morte súbita durante atividades esportivas seja reconhecida entre pessoas que desconheciam doença prévia, o uso rotineiro de ECO em atletas competitivos sem suspeita clínica de cardiopatia não parece justificável.

\subsection{Ecocardiograma intra-operatório de cirurgia cardía- ca e não cardíaca}

No campo da cirurgia cardíaca, o uso de ecocardiografia intraoperatória ganhou impulso com a técnica transesofágica, com superior vantagem à técnica epicárdica em adul-

\begin{tabular}{|c|c|}
\hline \multicolumn{2}{|l|}{$\begin{array}{l}\text { Tabela XLIII- Indicações para ecocardiografia transesofágica } \\
\text { intra-operatória }\end{array}$} \\
\hline Indicação & Classe \\
\hline $\begin{array}{l}\text { Valvoplastia mitral ou aórtica, cirurgias valvares } \\
\text { complexas com reimplante de artérias coronárias } \\
\text { (homoenxerto, cirurgia de Ross) }\end{array}$ & I \\
\hline Cirurgia de disseção aórtica com substituição valvar amorteça & I \\
\hline Cirurgia de cardiomiopatia hipertrófica obstrutiva & I \\
\hline $\begin{array}{l}\text { Cirurgia de defeitos cardíacos congênitos com uso de } \\
\text { circulação extracorpórea }\end{array}$ & I \\
\hline $\begin{array}{l}\text { Cirurgia de endocardite infecciosa sem definição prévia } \\
\text { da extensão do processo }\end{array}$ & I \\
\hline $\begin{array}{l}\text { Instabilidade hemodinâmica grave, sem respostas a } \\
\text { medidas terapêuticas, com dificuldade de saída de circulação } \\
\text { extra-corpórea, e dúvidas quanto ao grau de disfunção } \\
\text { ventricular ou da presença de defeito cirúrgico residual }\end{array}$ & I \\
\hline $\begin{array}{l}\text { Instabilidade hemodinâmica grave instalada, refratária } \\
\text { às medidas terapêuticas }\end{array}$ & I \\
\hline \multicolumn{2}{|l|}{ Durante cirurgias extra-cardíacas, com suspeita de disfunção ventricular } \\
\hline Instação de dispositivos intracardíacos (ex: "port-access") & I \\
\hline Substituição valvar por prótese & IIa \\
\hline Cirugia de Maze, correção de disseção aórtica sem troca valvar & IIa \\
\hline $\begin{array}{l}\text { Correção de aneurisma ventricular, resseção de tumor } \\
\text { ou de trombos }\end{array}$ & IIa \\
\hline $\begin{array}{l}\text { Detecção de ar intracavitário, ou embolia aérea durante } \\
\text { cardiotomia com extracorpórea, transplante cardíaco } \\
\text { e cirurgia neurológica. }\end{array}$ & IIa \\
\hline $\begin{array}{l}\text { Procedimentos cirúrgicos com alto risco de isquemia } \\
\text { miocárdica, infarto do miocárdio ou instabilidade hemodinâmica }\end{array}$ & IIa \\
\hline $\begin{array}{l}\text { Avaliação da função ventricular durante e após } \\
\text { revascularização miocárdica sem circulação extracorpórea }\end{array}$ & IIb \\
\hline Avaliação de cirurgia de pericárdio & IIb \\
\hline $\begin{array}{l}\text { Avaliação de isquemia induzida por estresse farmacológico, } \\
\text { estudo de perfusão miocárdica, de anatomia coronariana } \\
\text { e de patência de enxertos coronarianos }\end{array}$ & $\mathrm{IIb}$ \\
\hline
\end{tabular}

to e crianças, principalmente com o desenvolvimento de transdutores pediátricos. O impacto desta técnica é variável de acordo com a natureza do procedimento cirúrgico, sendo útil para orientação ao cirurgião de aspectos anatômicos ou funcionais em tempo real, para detecção imediata de defeitos residuais ou complicações passíveis de correção antes da saída de circulação extracorpórea ${ }^{106}$. O procedimento pode ser utilizado também em cirurgia cardíaca sem circulação extracorpórea ${ }^{107}$. Em cirurgias extra-cardíacas, o uso do ETE intra-operatório tem se difundido para monitorização contínua da função ventricular em pacientes com doença arterial coronariana conhecida ou suspeita, particularmente em cirurgias vasculares arteriais de grande porte. O procedimento pode causar disfagia pós-operatória em adultos. Discreto compromentimento superficial do esôfago pode ocorrer em crianças. A heparinização sistêmica não é, via de regra, contraindicação à intubação esofageana prolongada, e complicações hemorrágicas do esôfago são raras.

\subsection{Orientação de procedimentos intervencionistas na sala de hemodinâmica}

O ecocardiograma é necessário como técnica auxiliar na sala de cateterismo, em certos procedimentos terapêuticos 
intervencionistas, pelo método transtorácico(ETT) ou transesofágico(ETE). Seu emprego não se restringe unicamente ao procedimento, sendo de igual importância na seleção dos candidatos e no acompanhamento tardio dos resultados. A atrioseptostomia de Raskind, procedimento intervencionista pioneiro realizado na sala de cateterismo, continua sendo amplamente empregada nos dias atuais. Em ocasiões especiais, pode ser realizada à beira do leito, sob orientação exclusiva do ETT, quando não há disponibilidade de sala de cateterismo ou quando a remoção do paciente da sala de cuidados intensivos representa risco importante ${ }^{108}$. Na oclusão de defeitos septais atriais por dispositivos introduzidos por via percutânea, é indispensável o ETE não só para seleção de candidatos, mas sobretudo na sala de hemodinâmica para posicionamento e liberação da prótese, além da avaliação imediata de "shunts" residuais (classe I), bem como seguimento tardio ${ }^{109,110}$. OETE pode ser útil para implante de endopróteses aórticas para tratamento de aneurismas, dissecções, hematomas ou úlceras parietais da aorta torácica (classe IIb) ${ }^{106}$. Ouso rotineiro daECOna sala de hemodinâmica para oclusão do canal arterial, bem como para valvoplastia mitral, valvoplastia pulmonar ou aórtica e aortoplastia de coarctações aórticas, não é indispensável, exceto para avaliação imediata de complicações. Durante estudos eletrofisiológicos para ablação por radiofrequência de focos de fibrilação atrial com cateter o ETE pode ser utilizado. Nesta situação, o estudo com ultra-som intracardíaco poderá ser rotineiro no futuro. Embora raros, os ferimentos iatrogênicos na sala de hemodinâmica, suspeita de perfuração cardíaca e tamponamento, exigem a realização imediata de eco.

\subsection{Doenças sistêmicas com envolvimento cardíaco}

A indicação de ECO em doenças sistêmicas vai depender da prevalência de cardiopatia associada, das características do envolvimento cardíaco peculiar a cada situação e da suspeita clínica de envolvimento cardíaco, a exemplo da relação da doença arterial coronariana e diabetes. Pacientes renais crônicos podem desenvolver hipertrofia miocárdica importante, que dificulta a pesquisa de isquemia miocárdica por coronariopatia. Um padrão de hipertrofia miocárdica concêntrica e difusa ao ecocardiograma pode ser encontrado na amiloidose. Certas neoplasias (mama, pulmão,etc) podem determinar metástases pericárdicas silenciosas detectáveis ao ECO. O ECO é necessário para acompanhamento da função miocárdica durante quimioterapia por drogas cardiotóxicas. O ECO também éútil na avaliação cardiológica de certas colagenoses, como no lupus eritematoso sistêmico, que pode determinar derrame pericárdico e vegetações valvares trombóticas não bacterianas, e na esclerodermia (hipertensão pulmonar).

\section{Referências}

1. Lima CO, Martinez EE, Franken RA et al. Consenso Socesp-SBC sobre Ecocardiografia-Capítulo dos Consensos sobre Métodos em Cardiologia. Arq $\mathrm{Br}$ Cardiol 1995; 65: 459-68.

2. Barbosa ET. Critérios para solicitação de exames complementares do aparelho cardiovascular. Comissão de Legislação, Ética e Defesa Profissional da SBC. Arq Br Cardiol 1997; 68: http://publicacoes.cardiol.br/consenso /6803/.

3. Cheitlin MD, Armstrong WF, Aurigemma GPet al. ACC/AHA 2003 guidelines for the clinical applications of echocardiography: a report of the American College of Cardiology/American Heart Association Task Force on Practice Guidelines. http//www.acc.org/clinical/guidelines/echo/index.pdf.

4. Borow KM. An integrated approach to the noninvasive assessment of left ventricular systolic and diastolic performance. In: Sutton MST. Textbook of Adult and Pediatric Echocardiography an Doppler. Oxford: Blackwell Scientific Publications; 1989. p.97.

5. Suga H, Sagawa K, Shoukas AA. Load independence of the instantaneous pressure-volume ratio of the canine left ventricle and effects of epinephrine and heart rate on the ratio. Circ Res 1973; 32: 314.

6. Suga H, Sagawa K. Instantaneous pressure-volume relationships and their ratio in the excised, supported canine left ventricle. Circ Res 1974; 35: 117.

7. Grossman W, BraunwaldE, Mann T, McLaurin LP, Green LH. Contractile State of the Left Ventricle in Man as Evaluated from End-systolic Pressure-Volume Relations. Circulation 1977; 56: 845-52.

8. Marsh JD, Green LH, Wynne J, Cohn PF, Grossman W. Left ventricular end-systolic pressure-dimension and stress-length relations in normal human subjects. Am J Cardiol 1979; 44: 1311.

9. Borow KM, Neumann A, Wynne J. Sensitivity of End-systolic Pressure-Dimension and Pressure-Volume Relations to the Inotropic State in Humans. Circulation 1982; 65: 988-97.

10. Schiller NB, Shah PM, Crawford Metal. Recommendations for quantitation of the left ventricle by two-dimensional echocardiography Committee on Standards, Subcommittee on Quantitation of Two-Dimensional Echocardiograms. J Am Soc Echocardiogr 1989; 2: 358-67.

11. Sahn DJ, DeMaria A, Kisslo J, Weyman A. Recommendations regarding quantitation in M-mode echocardiography: results of a survey of echocardiographic measurements. Circulation 1978; 58: 1072-83.
12. Teichholz LE, Kreulen T, Herman MV, Gorlin R. Problems in echocardiographic volume determinations - echocardiographic-angiographic correlations in the presence or absence of asynergy. Am J Cardiol 1976; 37: 7-11.

13. Dougherty AH, Naccarelli GV, Gray EL, Hicks CH, Goldstein RA. Congestive heart failure with normal systolic function. Am J Cardiol 1984; 54: 778-82.

14. Topol EJ, Traill TA, Fortuin NJ. Hypertensive hypertrophic cardiomyopathy of the elderly. N Engl J Med 1985; 312: 277-83.

15. Soufer R, Wohlgelernter D, Vita NA et al. Intact systolic left ventricular function in clinical congestive heart failure. Am J Cardiol 1985; 55: 1032-6.

16. Lorell BH. Significance of diastolic dysfunction of the heart. Annu Rev Med 1991; 42: 411-36.

17. Dodek A, Kassebaum DG, Bristow JD. Pulmonary edema in coronary-artery disease without cardiomegaly: paradox of the stiff heart. N Engl J Med 1972;286: 1347-50.

18. Dougherty AH, Naccarelli GV, Gray EL, Hicks CH, Goldstein RA. Congestive heart failure with normal systolic function. Am J Cardiol 1984; 54: 778-82.

19. Nishimura RA,Abel MD, Hatle LK, Tajik AJ.Assessment of diastolic function of the heart: Background and current applications of Doppler echocardiography. Part II. Clinical studies. Mayo Clin Proc 1989; 64: 181-204.

21. Lorell BH. Significance of diastolic dysfunction of the heart. Annu Rev Med 1991; 42: 411-36.

20. Hirota Y. Aclinical study of left ventricular relaxation. Circulation 1980; 62: 756-63.

22. Ommen SR, Nishimura RA, Appleton C et al. Clinical utility of Doppler echocardiography and tissue Dopple imaging in the estimation of left ventricular filling pressures. A comparative simultaneous Doppler-catheterization study. Circulation 2000; 102: 1788-94.

23. Pinamonti B, Di Lenarda, Sinagra G et al. Restrictive left ventricular filling pattern in dilated cardiomyopathy assessed by Doppler echocardiography: clinical, echocardiographyc and hemodynamic correlations and prognostic implications. J Am Coll Cardiol 1993; 22: 808-15.

24. Acquatella H, Catalioti F, Gomez-Mancebo JR, Davalos V, Villalobos L. Long-term control of Chagas disease in Venezuela: effects on serologic findings, electrocardiographic abnormalities, and clinical outcome. Circulation 1987; 76: 556-62.

25. Sousa ACS. Estudo da função sistólica e diastólica do ventrículo esquerdo de pacientes chagásicos nas formas indeterminadas, cardíaca crônica e digestiva, submetidos ao esforço isométrico contínuo e a ação de um vasodilatador sistêmi- 
co, por meio de ecocardiografia e da angiocardiografia nuclear [Tese para obtenção do título de Doutor em Medicina]. Faculdade de Medicina de Ribeirão Preto da Universidade de São Paulo: Ribeirão Preto, 1987.

26. Acquatella H, Schiller NB, Puigbó JJ et al. M-mode and Two-dimensional Echocardiography in Chronic Chagas' Heart Disease. A Clinical and Pathologic Study. Circulation 1980; 62: 787-99.

27. Ortiz J, Pereira-Barreto AC, Matsumoto AY et al. Alteração contrátil segmentar na forma indeterminada da Doença de Chagas. Estudo ecocardiográfico. Arq Bras Cardiol 1987; 49/4: 217-20.

28. Marin-Neto JA, Bromberg-Marin G, Maciel BC et al. Cardiac autonomic impairment and early damage involving the right ventricle are independent phenomena in Chagas' disease. Int J Cardiol 1998; 65: 261-9.

29. Pereira-Barreto AC, Ortiz J, Mady C et al. Estudo ecocardiográfico na forma indeterminada da doença de Chagas. Correlação com biópsia endocárdica. Arq Bras Cardiol 1981; 37(supl.1): 168

30. Friedmann AA, Armelin E, Leme LEG et al-Desempenhoventricular na Doença de Chagas. Relações ecocardiográficas na miocardiopatia com distúrbio dromótropo e na fase pré-clínica. Arq Bras Cardiol 1981; 36: 23-7.

31. Almeida-Filho OC, Maciel BC, Schmidt A, Pazin-Filho A, Marin-Neto JA. Minor segmental dyssynergy reflects extensivemyocardial damage and global left ventricle dysfunction in chronic chagas disease. J Am Soc Echocardiogr 2002; 15: 610-6.

32. Miro J, Chartrand C, Kangah M, Van Doesburg NH, Fouron JC. Usefulness of non-invasive indices in the monitoring of heart-transplanted pediatric patients. Clin Transplant 1991; 5: 427-34.

33. Moidl R, Chevtchik O, Simon P et al. Noninvasive Monitoring of peak filling rate with acoustic quantification echocardiography accurately detects acute cardiac allograft rejection. J Heart Lung Transplant 1999; 18: 194-201.

34. Aziz TM, Burges MI, Rahman NA, Campbell CS, DeiraniyaAK, Yonan NA. Risk factors for tricuspid valve regurgitation after orthotopic heart transplantation. Ann Thorac Surg 1999; 68: 1247-51.

35. Larsen RL, Applegate PM, Dyar DA et al. Dobutamine stress echocardiography for assessing coronary artery disease after transplantation in children. J Am Coll Cardiol 1998; 32: 515-20.

36. Porea TJ, Dreyer ZE, Bricker JT, Mahoney DH Jr. Evaluation of left ventricular function in asymptomatic children about to undergo anthracycline-based chemotherapy for acute leukemia: an outcome study. J Pediatr hematol oncol 2001; 23: 420-3.

37. Hashimoto I, Ichida F, Miura M et al. Automatic border detection identifies subclinical anthracycline cardiotoxicity in children with malignancy. Circulation 1999; 11; 99: 2367-70.

38. Cottin Y, L'huillier I, Casasnovas O et al. Dobutamine stress echocardiography identifies anthracycline cardiotoxicity. Eur J Echocardiogr 2000; 1: 180-3.

39. Nishimura RA,Appleton Cp, Redfield MM, Ilstrup M, Holmes DR, Tajik AJ. Noninvasive Doppler echocardiographic evaluation of left ventricular filling pressures in patients with cardiomyopathies: a simultaneous Doppler echocardiographic and cardiac catheterization study. JAm Coll Cardiol 1996; 28: 1226-33.

40. Nagueh SF, Bachinski LL, Meyer D et al. Tissue Doppler imaging consistently detects myocardial abnormalities in patients with hypertrophic cardiomyopathy and provides a novel means for an early diagnosis before and independently of hypertrophy. Circulation 2001; 104: 128-30.

41. Dhir M, Nagueh SF. Echocardiography and prognosis of heart failure. Curr Opin Cardiol 2002; 17: 253-6.

42. Rajagopalan N, Garcia MJ, Rodriguez L et al. Comparison of new Doppler echocardiographic methods to differentiate constrictive pericardial heart disease and restrictive cardiomyopathy. Am J Cardiol 2001; 87: 86-94.

43. Brindeiro Filho D, Cavalcanti C. O Valor da ecodopplercardiografia na identificação diagnóstica e no manuseio da endomiocardiofibrose. Arq Bras Cardiol 1996; 67: 279-84.

44. Harken DE, SoroffHS, TaylorWJ, LefemineAA, Gupta SK, Lunzer S. Partial and complete prosthesis in aortic insufficiency. J Thorac Cardiovasc Surg 1960; 40: 744-62.

45. Starr A, Edwards ML. Mitral replacement: Clinical experience with a ball-valve prosthesis. Ann Surg 1961; 154: 726-40.

46. ACC/AHA Guideline for the Management of Patients With Valvular Heart Disease. J Am Coll Cardiol 1988; 32: 1486-588.

47. ACC/AHA Guidelines for the Clinical Application of Echocardiography: Executive Summary. J Am Coll Cardiol 1997; 29: 862-79.

48. Autore C, Agati L, Piccininno M, Lino S, Musaro S. Role of echocardiography in acute chest pain syndrome. Am J Cardiol 2000; 86(suppl): 41G-42G.

49. Muscholl MW, Oswald M, Mayer C, von Scheidt W. Prognostic value of 2D echocardiography in patients presenting with acute chest pain and non-diagnostic ECG for ST-elevation myocardial infarction. Intern J Cardiol 2002; 84: 217-25.

50. Selker HP, Zalenski RJ,Antman EM et al. An evaluation of technologies for identifying acute cardiac ischemia in the emergency department: a report from a National Heart Attack Alert Program Working Group [erratum appears in Ann Emerg Med 1997; 29: 310]. Ann Emerg Med 1997; 29: 13-87.

51. Marcovitz PA, Shayna V, Horn RA, HepnerA,Armstrong WF. Value of dobutami- ne stress echocardiography in determining the prognosis of patients with known or suspected coronary disease. Am J Cardiol 1996; 78: 404-8.

52. Marwick T, Willemart B, D'Hondt AM et al. Selection of the optimal nonexercise stress for the evaluation of ischemic regional myocardial dysfunction and malperfusion. Comparison of dobutamine and adenosine using echocardiography and 99 mTc-MIBI single photon emission computed tomography. Circulation 1993; 87: 345-54.

53. Arruda AM, Das MK, Roger VL et al. Prognostic value of exercise echocardiography in 2,632 patients $>65$ years of age. J Am Coll Cardiol 2001; 37: 1036-41.

54. Picano E, Pingitore A, Sicari R et al. Stress echocardiographic results predict risk of reinfarction early after uncomplicated acute myocardial infarction: largescale multicenter study. Echo Persantine International Cooperative (EPIC) Study Group. J Am Coll Cardiol 1995; 26: 908-13.

55. Eagle KA, Brundage BH, Chaitman BR et al. ACC/AHA guidelines for perioperative cardiovascular evaluation for noncardiac surgery. A report of the American College of Cardiology/American Heart Association Task Force on Practice Guidelines (Committee on Perioperative Cardiovascular Evaluation for Noncardiac Surgery). J Am Coll Cardiol 1996; 27: 910-48.

56. Cigarroa CG, deFilippi CR, Brickner ME et al. Dobutamine stress echocardiography identifies hibernating myocardium and predicts recovery of left ventricular function after coronary revascularization. Circulation 1993; 88: 430-6.

57. Mathias W, Arruda AL, Andrade JL, Campos O, Porter TR. Endocardial border delineation during dobutamine infusion through use of contrast echocardiography. Echocardiography 2002; 19: 1-6.

58. Mulvagh SL, DeMaria AN, Feinstein SB et al. Contrast echocardiography: Current and future applications. J Am Soc Echocardiogr 2000; 13: 331-42.

59. Tsutsui JM, Dourado PM, Chagas ACP et al. Ecocardiografia com perfusão em tempo real. Correlação entre as alterações de contratilidade e perfusão em um modelo experimental de infarto e reperfusão. Arq Bras Cardiol 2001; 77(Supl 1): 36

60. PorterTR, Xie F, Silver M, Kricsfield D, O'Leary E. Real-time perfusion imaging with low mechanical index pulse inversion Doppler imaging. J Am Coll Cardiol 2001; 37: 748-53.

61. Iliceto S. Marangelli V, Memmola C, Rizzon P. Transesophageal Doppler echocardiography evaluation of coronary blood flow velocity in baseline conditions and during dipyridamole-induced coronary vasodilatation. Circulation 1991; 83: 61.

62. Hozumi T, Yoshida K, Ogata Y et al. Noninvasive assessment of significant left anterior descending artery stenosis by coronary flow velocity reserve with transthoracic color Doppler echocardiography. Circulation 1998; 97: 1557-62.

63. Wei K, JayaweeraAR, Firoozan S et al. Quantification of myocardial blood flow with ultrasound-induced destruction of microbubbles administered as a constant venous infusion. Circulation 1998; 97: 473-83.

64. Gottdiener JS, Livengood SV, Meyer OS et al. Should echocardiography be performed to assess effects of antihypertensive therapy? J Am Coll Cardiol 1995; 25 424-30.

65. Yock PG, Popp RL. Noninvasive estimation of right ventricular systolic pressure by Doppler ultrasound in patients with tricuspid regurgitation. Circulation 1984; 70: 657-62.

66. Chan RK, Johns JA, Calafiore P. Clinical implications of the morphological features of central pulmonary artery thromboemboli shown by transoesophageal echocardiography. Br Heart J 1994; 72: 58-62.

67. Brugada P, Brugada J. Right bundle branch block, persistent ST segment elevation and sudden cardiac death: a distinct clinical and electrocardiographic syndrome. J Am Coll Cardiol 1992; 20: 1391-6.

68. Fuster V, Rydén LA,Asinger RW et al.ACC/AHA/ESC Guidelines for the management of patients with atrial fibrillation. J Am Coll Cardiol 2001; 38: 1266-1.

69. Dittrich HC, Errickson JS, Schneiderman T, Blacky AR, Savides T, Nicod PH. Echocardiographic and clinical predictors for outcome of elective cardioversion of atrial fibrillation. Am J Cardiol 1989; 63: 193-7.

70. Black IW, Fatkin D, Sagar KB et al. Exclusion of atrial thrombus by transesophageal echocardiography does not preclude embolism after cardioversion of atrial fibrillation. A multicenter study. Circulation 1994; 89: 2509-13.

71. Manning WJ, Siverman DI, Gordon SPF, Krumholz HM, Douglas P. Cardioversion from atrial fibrillation without prolonged anticogulation with use of transesophageal echocardiography to exclude the presence of atrial thrombi. N Engl J Med 1993; 328: 750-5.

72. Klein AL, Grim RA, Murray RD et al. Use of transesophageal echocardiography to guide cardioversion in patients with atrial fibrillation. N Engl J Med 2001; 344: 1411-20

73. Stoddard MF, Dawkins PR, Prince CR, Ammash NM. Left atrial appendage thrombus is not uncommon in patients with acute atrial fibrillation and a recent embolic event: A transesophageal echocardiographic study. J Am Coll Cardiol 1995; 25: 452-9.

74. Santiago D, Warshofsky M, Li Mandri G et al. Left atrial appendage function and thrombus formation in atrial fibrillato-flutter: a transesophageal echocardiographic study. J Am Coll Cardiol 1994; 24: 159-64.

75. Achiron R, Glaser J, Gelernter I, Hegesh J, Yagel S. Extended fetal echocardiographic examination for detecting cardiac malformations in low risk pregnancies. $\mathrm{Br}$ Med J 1992;304: 671-4. 
76. Stumpflen I, Stumpflen A, Wimmer M, Bernaschek G. Effect of detailed fetal echocardiography as part of routine prenatal ultrasonographic screening in detection of congenital heart disease. Lancet 1996; 348: 854-7.

77. Bromley B, Estroff JA, Sanders S et al. Fetal echocardiography: accuracy and limitations at high risk and low risk for heart defects. Am J Obstet Gynecol 1992; 166: $1473-81$.

78. Ott WJ. The accuracy of antenatal fetal echocardiography screening in high-and low-risk patients. Am J Obstet Gynecol 1995; 172: 1741-8.

79. Smythe JF, Copel JA, Kleiman CS. Outcome of prenatally detected cardiac malformations. Am J Cardiol 1992; 69: 1471-4.

80. Zielinsky P. Role of prenatal echocardiography in the study of hypertrophic cardiomyopathy in the fetus. Echocardiography 1991; 8: 661-8.

81. Allan LD. Indications for fetal echocardiography. In: Allan L, Hornberger L, Sharland G. Textbook of Fetal Cardiology. London; Greenwich Medical Media, 2000: 47-53.

82. Bierman FZ, Willians RG. Subxiphoid two-dimensional imaging of the interatrial septum in infants and neonates with congenital heart disease. Circulation 1979; 60: 80-90.

83. Leung MP, Mok CK, Lau KC, Lo Ryeung CY. The role of cross sectional echocardiography and pulsed Doppler ultrasound in the manegement of neonates in whom congenital heart disease is suspected. A prospective study. Br Heart J 1986; 56: 73-82.

84. Huhta JC, Cohen M, Gutgesell HP. Patency of ductus arteriosus in normal neonates: two-dimensional echocardiography vs Doppler assessment. J Am Coll Cardiol 1984; 4: 561-4.

85. Alboliras ET, Seward JB, Hagler DJ, Danielson GK, Puga FJ, Tajik AJ. Impact of two-dimensional and Doppler echocardiography on care of children aged two years and younger. Am J Cardiiol 1988; 61: 166-9.

86. Bash SE, Huhta JC, Vick GW, Gutgesell HP, Ott DA. Hypoplastic left heart syndrome: is echocardiography accurate enough to guide surgical palliation? J Am Coll Cardiol 1986; 7: 610-6.

87. Krabill KA, Ring WS, Foker JE et al. Echocardiographic versus cardiac catheterization diagnosis of infants with congenital heart disease requiring cardiac surgery. Am J Cardiol 1987; 60: 351-4.

88. Shub C et al. Sensitivity of two-dimensional echocardiography in the direct visualization of atrial septal defects utilizing the subcostal approach: experience with 154 patients. J Am Coll Cardiol 1983; 4: 127.

89. Ettedgui JA, Siewers RD, Anderson RH et al. Diagnostic echocardiographic features of the sinus venosus defect. Br Heart J 1991; 64: 329-1.

90. Radzik D, Davignon A, van Doesburg N et al. Predictive factors for spontaneous closure of atrial septal defects diagnosed in the first 3 months of life. J Am Coll Cardiol 1991; 22: 851-3

91. Lipshultz SE, Sanders SP, Mayer JE, Colan SD, Lock JE. Are routine preoperative cardiac catheterization and angiography necessary before repair of ostium primum atrial septal defect? J Am Coll Cardiol 1988; 11:373-8.

92. Sutherland GR, Godman MJ, Smallhorn JF, Guiterras P, Anderson RH, Hunter S Ventricular septal defects: two-dimensional echocardiographic and morphological correlations. Br Heart J 1982; 47: 316-28.
93. Capelli H, Andrade JL, Somerville J. Classification of the site of ventricular septal defect by 2-dimensional echocardiography. Am J Cardiol 1983; 51: 1474-80.

94. Lima CO, Sahn DJ, Valdes-Cruz LM et al. Noninvasive prediction of transvalvular pressure gradient in patients with pulmonary stenosis by quantitative two-dimensional echocardiographic Doppler studies. Circulation 1983; 67: 866-71.

95. Simpson IA, Sahn DJ, Valdes-Cruz LM, Chung KJ, Sherman FS, Swensson RE. Color Doppler flow mapping in patients with coarctation of the aorta: new observations and improved evaluation with color flow diameter and proximal acceleration as predictors of severity. Circulation 1988; 77: 736-44.

96. Capannari TE, Daniels SR, Meyers RA, Schwartz DC, Kaplan S. Sensitivity, specificity and predictive value of two-dimensional echocardiography in detecting coronary artery aneurisms in patients with Kawasaki disease. J Am Coll Cardiol 1986; 7: 355-60.

97. Lewis AB. Prognostic value of echocardiography in children with idiopathic dilated cardiomyopathy. Am Heart J 1994; 128: 133-6.

98. Lipshultz SE, Sanders SP, Goorin AM, Krischer JP, Sallan SE, Colan SD. Monitoring for anthracycline cardiotoxicity. Pediatrics 1994; 93: 433-7.

99. Guidelines for the diagnosis of rheumatic fever. Jones Criteria, 1992 update. Special Writing Group of the Committee on Rheumatic Fever, Endocarditis, and Kawasaki disease of the Council on Cardiovascular Disease in the Young of the American Heart Association. JAMA 1993; 2069-73.

100. Kohli V. Infective endocarditis. Indian J Pediatr 2002; 69: 333-9.

101. Cyran SE, Kimball TR, Meyer RA et al. Efficacy of intraoperative transesophageal echocardiography in children with congenital heart disease. Am J Cardiol 1989; 63: 594-8.

102. Stumper OF, Sreeram N, Elzenga NJ, Hess J, Sutherland GR. Transesophageal echocardiography in children with congenital heart disease: an initial experience. J Am Coll Cardiol 1989; 16: 433-41.

103. Kimball TR. Pediatric stress echocardiography. Pediatr Cardiol 2002; 23:347-57.

104. Campos O, Andrade JL, Bocanegra J et al. Physiologic multivalvular regurgitation during pregnancy: a longitudinal Doppler echocardiographic study. Int J Cardiol 1993; 40: 265-72.

105. Reimold SC, Rutherford JD. Valvular Heart Disease in Pregnancy. N Engl J Med: 349: 52-9.

106. Fischer $\mathrm{CH}, \mathrm{Campos} \mathrm{F}^{\circ}$, Fonseca JHAP et al. Uso da ecocardiografia transesofágica para implante de endoprótese (stent) aórtica. Experiência inicial. Arq Bras Cardiol 2001; 77: 1-8.

107. Moises VA, Mesquita CB, Campos O et al. Importance of intraoperative transesophageal echocardiography during coronay artery surgery without cardiopulmonary bypasss. J Am Soc Echocardiogr 1998; 11: 1139-44

108. Allan LD, Leanage R, Wainwright R, Joseph MC, Tynan M. Balloon atrial septostomy under two dimensional echocardiographic control. Br Heart J 1982; 47: 41-3.

109. Pontes Jr SC. A Importância da Ecocardiografia Transesofágica na Avaliação Morfológica dos Defeitos Septais Atriais. Revista Brasileira de Ecocardiografia 1999; 31: 25-37.

110. Masura J, Gavora P, Formanek M. Transcatheter closure of secundum atrial septal defects using the new self-centering Amplatzer septal occluder; initial human experience. Cathet Cardiovasc Diagn 1997; 42: 388-93. 